\title{
Removal of toluene as a biomass tar surrogate in a catalytic non-thermal plasma process
}

Bin $\mathrm{Xu}^{1,2}$, Jianjun Xie ${ }^{1 *}$, Hao Zhan ${ }^{1,2}$, Xiuli Yin ${ }^{1}$, Chuangzhi Wu ${ }^{1}$, Hao Liu ${ }^{3}$

1, CAS Key Laboratory of Renewable Energy, Guangdong Provincial Key Laboratory of New and Renewable Energy Research and Development, Guangzhou Institute of Energy Conversion, Chinese Academy of Sciences, Guangzhou 510640, China

2, University of Chinese Academy of Sciences, Beijing 100049, China

3, Department of Architecture and Built Environment, Faculty of Engineering, University of Nottingham, University Park, Nottingham NG7 2RD, The United Kingdom

*Corresponding author: Tel.: +86 208705 7757. E-mail address: xiejj@ms.giec.ac.cn (J. Xie).

\begin{abstract}
In this study, a packed-bed dielectric barrier discharge (DBD) reactor was developed to investigate the removal of biomass tar in a fuel gas atmosphere. Toluene was used as the tar surrogate and the catalyst used was a Nickel-based catalyst $\left(\mathrm{Ni} / \mathrm{Y}-\mathrm{Al}_{2} \mathrm{O}_{3}\right)$ because of its high activity and low cost. In addition, other two kinds of packing materials (glass pellets and $\psi-\mathrm{Al}_{2} \mathrm{O}_{3}$ pellets) were employed to make a comparison with the $\mathrm{Ni} / \mathrm{\nu}-\mathrm{Al}_{2} \mathrm{O}_{3}$ catalyst. The research has focused on the removal efficiency of toluene and the effects of carrier gas, reaction temperature, Ni loading and concentration of toluene. The results indicated that two supplementary packing materials could not realize an effective removal of toluene. On the contrary, $\mathrm{Ni} / \mathrm{Y}-\mathrm{Al}_{2} \mathrm{O}_{3}$ combined with plasma showed a significant synergetic effect and hence a great toluene removal potential. On one hand, the removal efficiency initially decreased within the temperature range of $200-300^{\circ} \mathrm{C}$ and then significantly increased within the temperature of $300-400{ }^{\circ} \mathrm{C}$ during plasma-catalytic process. At the optimal temperature of $400{ }^{\circ} \mathrm{C}$, the toluene removal efficiency could reach the maximum values of $80.2 \%, 91.7 \%$ and $100.0 \%$ when the Ni loading was 3, 5 and $10 \mathrm{wt} \%$, respectively. On the other hand, an increase in the inlet toluene concentration slightly reduced removal efficiency but increased the energy efficiency, reaching the highest value of $16.9 \mathrm{~g} / \mathrm{kWh}$. The introduction of plasma enhanced the methanation reaction of the fuel gas occurring in the catalytic process, which was favorable at high temperatures. Based on these findings, the mechanisms and pathways of toluene destruction in the plasma-catalytic process were proposed and elucidated.
\end{abstract}

Key words: tar removal; non-thermal plasma; toluene; plasma-catalytic process; $\mathrm{Ni} / \mathrm{Y}-\mathrm{Al}_{2} \mathrm{O}_{3}$ catalyst 


\section{Introduction}

With the rapid depletion of fossil fuels and the growing aggravation of the subsequent greenhouse effect, biomass as an important renewable energy source has received considerable attention over the recent years. In terms of energy utilization efficiency and simplification of application, biomass gasification can be regarded as one of the most promising technologies which converts biomass to a fuel gas or synthesis gas [1]. The fuel gas can be combusted in gas engines and turbines to generate electricity and heat, while the high quality synthesis gas can be used for fuel cells and Fischer-Tropsch synthesis $[2,3]$. However, there are many undesirable byproducts/pollutants formed during the gasification process, for instance, fly ash, $\mathrm{NO}_{x}, \mathrm{SO}_{2}$ and tar. Tar, one of the most troublesome contaminants in the fuel gas or synthesis gas [4], is a complex mixture of condensable hydrocarbons and will condense when the process temperature is lower than its dew point, resulting in fouling, clogging and corrosion problems in subsequent process units such as pipes, filters and engines[5]. Therefore, tar removal or cracking to light gaseous components is an essential process for the efficient use of the raw fuel gas derived from biomass gasification.

Many purification methods, including mechanical separation, thermal cracking and catalytic reforming, have been used for tar removal in biomass gasification processes [6]. Mechanical separation is a wide common approach, while it causes secondary environment pollution and some energy loss [6]. Thermal cracking of tars requires a very high temperature $\left(>1000^{\circ} \mathrm{C}\right)$ to obtain the good performance, resulting in a higher energy consumption and lower energy efficiency [7]. Catalytic reforming of tars is regarded as a more attractive tar removal technology, due to its potential in converting tars into valuable light gaseous products at low temperatures and regulating the $\mathrm{H}_{2} / \mathrm{CO}$ ratio in the synthesis gas. However, it still faces two major challenges: firstly, the reaction process is endothermic, consequently, high temperature is likely required to achieve the optimal results; secondly, there is an unavoidable disadvantage during the reaction process that catalysts can be easily deactivated by coke deposition, sintering and poisoning [8].

Recently, the application of non-thermal plasma technology has attracted significantly attention due to its capability of activating reactive molecules at ambient pressure and room temperatures. In a non-thermal plasma, although the gas temperature remains in the range of room temperature, the temperature of energetic electrons can reach $10^{4}-10^{5}$ K. In such case, the sufficient energy can break chemical bonds of reactive molecules and, produce a variety of reactive species including free radicals, excited atoms, ions, and molecules [9]. Several investigations on tar removal using nonthermal plasma, including dielectric barrier discharge (DBD) [10-12], pulsed corona discharge [13] and gliding arc discharge $[14,15]$, have been conducted. It has been reported that the plasma process can very efficiently eliminate tars or tar model compounds at low temperatures but the high energy consumption and the low selectivity of desired products may restrict its applications [12, 14]. The introduction of a catalyst to a non-thermal plasma tar reduction process can be a promising approach to solve the aforementioned issues by combining the advantages of non-thermal 
plasma and catalyst [16]. The combination of plasma and catalyst has the potential to generate a synergetic effect, which can lower the activation energy of tar cracking and improve the conversion of reactants, the selectivity of desired products, and consequently enhance the energy efficiency of the plasma-catalytic process [17-19]. The synergetic effect was successfully achieved in a tar removal process when using a pulse corona discharge reactor combined with $\mathrm{Y}-\mathrm{Al}_{2} \mathrm{O}_{3}[20]$. In a plasma process, the background gas (referring to carrier gas) is a very important factor, which exerts significant effect on both physical and chemical properties of plasma, such as the discharge current, species and numbers of reactive components, resulting in the variation of reaction performance [21, 22]. Abdelaziz et al. [23] found that the presence of oxygen could increase the positive pulse repetition rate but decrease the positive pulses amplitude of micro-discharges due to the electronegativity of oxygen, and the highest decomposition efficiencies of naphthalene was obtained in pure nitrogen in a surface dielectric barrier discharge reactor. Yu et al. [24] studied the effect of different carrier gases on the electrical characteristics of gliding arc discharge and naphthalene destruction. They found that the argon plasma had the highest discharge current but the lowest destruction efficiency, and the highest decomposition rate was obtained in oxygen plasma. However, most of previous studies on tar removal in plasma processes have used noble gas like nitrogen or helium as the carrier gas for tar, which is very different from the real fuel gas derived from biomass gasification. Few studies have investigated the removal of biomass tar in a fuel gas atmosphere by combining plasma and catalyst, and hence the tar removal behavior and the synergetic effect in the plasma-catalytic process are not really understood.

The present study aims to demonstrate the tar in a fuel gas atmosphere can be effectively removed by the combination of plasma and catalyst at a low energy input. In this work, a coaxial packed-bed DBD reactor has been designed and built for the removal of tar. Toluene was selected as a typical tar model compound as it is one of the main important compounds with high thermal stability among the biomass gasification tars. A synthetic fuel gas similar to that obtained from biomass gasification was adopted as the carrier gas. The effect of carrier gas (fuel gas or nitrogen), reaction temperature, $\mathrm{Ni}$ loading and concentration of toluene were investigated. In addition, other two packing materials, glass pellets and $\mathrm{v}-\mathrm{Al}_{2} \mathrm{O}_{3}$ pellets, were employed to make a comparison with the $\mathrm{Ni} / \mathrm{\psi}-\mathrm{Al}_{2} \mathrm{O}_{3}$ catalyst. The exhaust gas and liquid products were analyzed quantitatively or qualitatively to get insight into the possible destruction pathways of toluene.

\section{Experimental}

\subsection{Catalyst preparation}

The $\mathrm{Ni} / \mathrm{Y}-\mathrm{Al}_{2} \mathrm{O}_{3}$ catalysts with different Ni loadings $(3,5$, and $10 \mathrm{wt} \%)$ used in this work were prepared by a wet

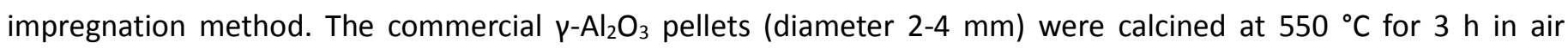


atmosphere prior to use. The appropriate weight of $y-\mathrm{Al}_{2} \mathrm{O}_{3}$ was added to aqueous solution of $\mathrm{Ni}\left(\mathrm{NO}_{3}\right)_{2} \cdot 6 \mathrm{H}_{2} \mathrm{O}$ and impregnated for overnight at ambient temperature. Subsequently, the catalyst precursor was dried at $120^{\circ} \mathrm{C}$ for $6 \mathrm{~h}$, and then calcined at $400{ }^{\circ} \mathrm{C}$ for $4 \mathrm{~h}$ in air atmosphere.

\subsection{Catalyst characterization}

The BET surface, pore volume and average pore diameter of catalysts were measured by $\mathrm{N}_{2}$ adsorption/desorption isotherms at $-196^{\circ} \mathrm{C}$ using a surface area analyzer (Micromeritics, ASAP2010). Before the measurement, the catalysts were degassed at $200{ }^{\circ} \mathrm{C}$ for $8 \mathrm{~h}$ under vacuum. Powder X-ray diffraction (XRD) measurements were performed on an X-ray diffractometer instrument (PANalytical, X'pert Pro MPD) with Cu Ka radiation operated at $40 \mathrm{kV}$ and $40 \mathrm{~mA}$. $\mathrm{H}_{2^{-}}$ temperature programmed reduction $\left(\mathrm{H}_{2}\right.$-TPR) measurements were carried out on a TPR instrument (Quantachrome, ChemStar). Before the measurement, $50 \mathrm{mg}$ sample was preheated in an $\mathrm{Ar}$ stream at $300^{\circ} \mathrm{C}$ for 30 minutes and then cooled to $40{ }^{\circ} \mathrm{C} . \mathrm{H}_{2}$-TPR was conducted with a gas mixture of 10 vol.\% $\mathrm{H}_{2}$ in $\mathrm{Ar}$ at a flow rate of $50 \mathrm{~mL} / \mathrm{min}$. The temperature was raised from $40^{\circ} \mathrm{C}$ to $900^{\circ} \mathrm{C}$ with a heating rate of $10^{\circ} \mathrm{C} / \mathrm{min}$.

\subsection{Experimental setup}

A schematic diagram of the experimental setup is shown in Fig.1. The experimental system consists of four units, including the toluene generation unit, DBD plasma reactor, electrical measurements unit and chemical analysis unit. Gaseous toluene was obtained by passing a nitrogen gas stream through a toluene bubbler submerged in a water bath kept a constant temperature. The Nitrogen stream containing gaseous toluene and carrier gas (fuel gas or nitrogen) were fully mixed in the mixing chamber before feeding to the DBD reactor. The fuel gas applied in this study was composed of 15 vol\% of $\mathrm{H}_{2}, 18$ vol\% of $\mathrm{CO}, 12$ vol\% of $\mathrm{CO}_{2}, 1.5$ vol\% of $\mathrm{CH}_{4}$ and 53.5 vol\% of $\mathrm{N}_{2}$, which simulates the real fuel gas derived from biomass gasification [25]. The flow rates of different gases were regulated by a set of mass flow controllers (MFC, Sevenstar, D07-series). The total flow rate and the concentration of toluene were kept at 0.06 $\mathrm{m}^{3} / \mathrm{h}$ (based on room temperature and atmospheric pressure) and $600 \mathrm{ppmv}\left(2.2 \mathrm{~g} / \mathrm{m}^{3}\right)$, respectively, in this study unless otherwise mentioned.

The DBD plasma reactor is made of a cylindrical corundum ceramic tube with the inner diameter of $20 \mathrm{~mm}$ and outer diameter of $25 \mathrm{~mm}$. The outer surface of the corundum ceramic tube is wrapped by a $200 \mathrm{~mm}$ long stainless steel mesh as the outer electrode, and the stainless steel mesh is connected to the ground through a capacitor ( $0.1 \mu \mathrm{F})$. A stainless steel rod (diameter $5 \mathrm{~mm}$ ) as the inner electrode is placed along the axis of the tube. The discharge gap between the inner electrode and the corundum ceramic tube is $7.5 \mathrm{~mm}$ with a corresponding discharge volume is $58.9 \mathrm{ml}$. Three kinds of packing materials, including $\mathrm{Ni} / \mathrm{\gamma}-\mathrm{Al}_{2} \mathrm{O}_{3}$ catalysts, commercial glass pellets (diameter $3 \mathrm{~mm}$ ) and $\mathrm{\gamma}-\mathrm{Al}_{2} \mathrm{O}_{3}$ pellets, 
were used in this work. In the experiments, the packing materials were directly placed in the discharge zone. To hold the packing materials, a stainless steel sieve plate was fixed at the end of inner electrode and located $30 \mathrm{~mm}$ below the lower border of the discharge zone, and the region between the edge of the discharge zone and the stainless steel sieve was filled with quartz sands (diameter 1-2 mm). To investigate the effect of reaction temperature, the DBD reactor was placed inside a temperature-controlled tubular furnace. The reaction temperature was measured by a K-type thermocouple located on the outside reactor tube wall at the midpoint of the discharge zone. When Ni/ $\mathrm{Y}^{-\mathrm{Al}_{2} \mathrm{O}_{3}}$ catalysts were selected as the packing material in the experiments, the catalysts were reduced in situ in flowing pure hydrogen at $400{ }^{\circ} \mathrm{C}$ for $2 \mathrm{~h}$ before each experiment.

The DBD plasma reactor was driven by an AC high voltage power supply (Nanjing Suman, CTP-2000K) with a peak voltage of $30 \mathrm{kV}$ and a frequency of $5-20 \mathrm{kHz}$. The frequency was kept at $9 \mathrm{kHz}$ in this study. The V-Q Lissajous method was used to determine the discharge power in the DBD plasma reactor. The charge stored in the reactor was determined by measuring the voltage across the capacitor $(0.1 \mu \mathrm{F})$. The high voltage applied to the DBD reactor was measured by a high voltage probe (Tektronix, P6015A). The signals of the applied voltage and the charge were recorded with a digital oscilloscope (Tektronix, DPO2024B). The discharge power of the DBD reactor was calculated by multiplying the area of Lissajous diagram with the frequency [26].

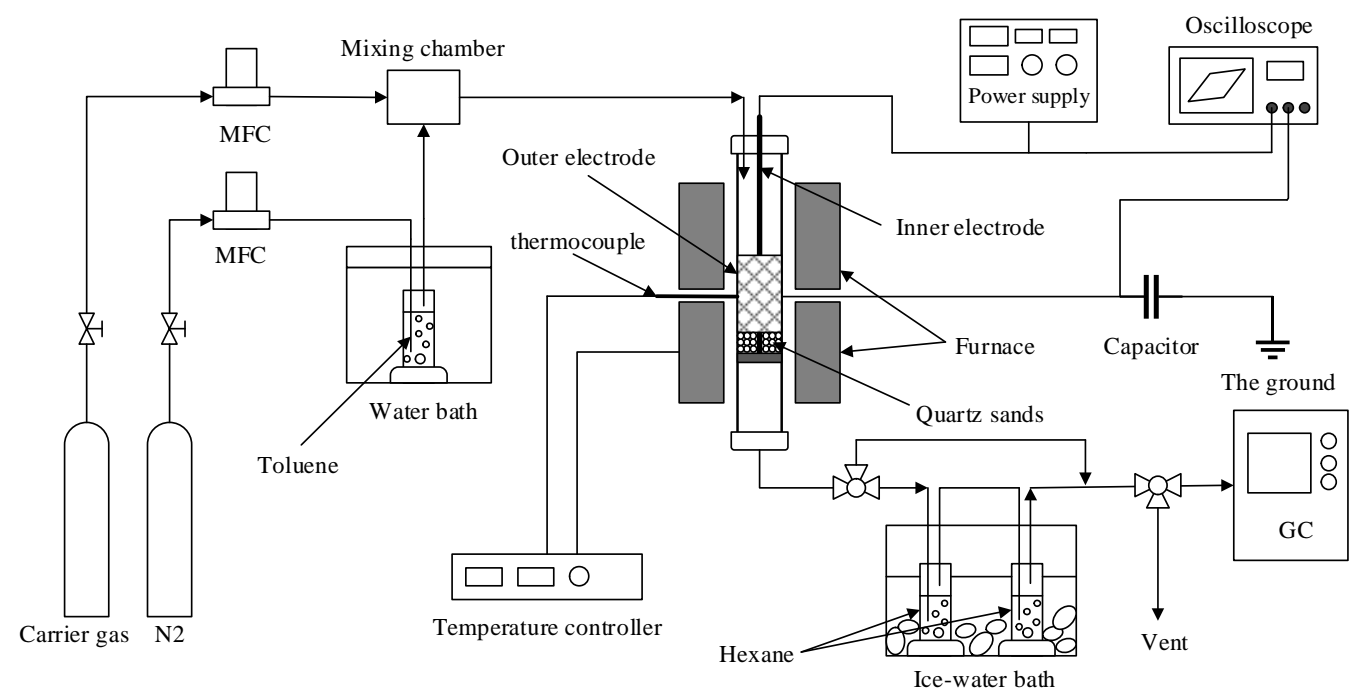

Fig.1. Schematic diagram of the experimental setup

\subsection{Methods of analysis}

The composition of the exhaust gas was analyzed by a gas chromatography (GC, Shimadzu, GC-2014) equipped with a flame ionization detector and a thermal conductivity detector for the analysis of $\mathrm{N}_{2}, \mathrm{H}_{2}, \mathrm{CO}, \mathrm{CO}_{2}, \mathrm{CH}_{4}, \mathrm{C}_{2} \mathrm{H}_{2}, \mathrm{C}_{2} \mathrm{H}_{4}$ and $\mathrm{C}_{2} \mathrm{H}_{6}$. The concentrations of toluene and benzene (one of the products generated by toluene destruction) were analyzed by another on-line GC (Fuli, 9790) equipped with a flame ionization detector (FID). During each experiment, 
an ice trap, consisting of two absorption bottles filled with $100 \mathrm{ml}$ hexane and placed in an iced water trap, was placed at the exit of the reactor to collect the liquid products. The liquids product dissolved in hexane was analyzed by an offline gas chromatography-mass spectrometry (GC-MS, Thermo Fisher, Trace 1300-ISQ) equipped with a DB-5 capillary column.

The toluene removal efficiency, tar removal efficiency and selectivity of benzene are defined as follows:

$\eta_{\text {toluene }}(\%)=\frac{[T]_{\text {in }}-[T]_{\text {out }}}{[T]_{\text {in }}} \times 100 \%$

$\eta_{\text {tar }}(\%)=\frac{[T]_{\text {in }}-\left([T]_{\text {out }}+[B]_{\text {out }}\right)}{[T]_{\text {in }}} \times 100 \%$

$S_{B}(\%)=\frac{6[B]_{\text {out }}}{7\left([T]_{\text {in }}-[T]_{\text {out }}\right)} \times 100 \%$

Where $[T]_{\text {in }},[T]_{\text {out }}$ represent the concentration of toluene at the inlet and the outlet of the reactor, respectively, and $[B]_{\text {out }}$ means the concentration of benzene at the outlet.

The specific energy input (SEI) of the plasma discharge, i.e. the ratio of the input energy to the gas flow rate, is defined as follows:

$\mathrm{SEI}(\mathrm{J} / \mathrm{L})=\frac{P_{D}(W)}{Q(L / \min )} \times 60$

Where $P_{D}$ represent the discharge power, and $\mathrm{Q}$ is the gas flow rate.

When evaluating the energy efficiency, both the DBD discharge energy and the additional heating energy from the furnace were taken into account to make the evaluation practically meaningful. Therefore, the energy efficiency of the toluene removal is defined as:

$\mathrm{E}(\mathrm{g} / \mathrm{kWh})=\frac{[\mathrm{m}]_{\text {removal }}(\mathrm{g} / \mathrm{min})}{\left[P_{D}(W)+P_{T}(W)\right] \times 60 / 3600000}$

Where $P_{T}$ is the heating power required to heat the gas stream from room temperature to target temperatures and $[\mathrm{m}]_{\text {removal }}$ are the grams of toluene removed per minute.

All measurements were conducted after the reaction reached a stable stage. After each experiment, the reactor was heated to $600{ }^{\circ} \mathrm{C}$ for $1 \mathrm{~h}$ in air atmosphere to remove carbon deposition and other contaminants formed in the experiment. The experimental data in this paper were the average value of three repeating runs which conducted within each experiment, their relative errors were found to be less than $5 \%$ and their error bars described by standard deviation were presented in each figure.

\section{Results and discussion}

\subsection{Catalyst characterization}

The specific surface area and pore structure of the packing materials used in this study are shown in Table.1. Clearly, 
the specific surface area of glass pellet is substantially lower than other packing materials. Moreover, for $\mathrm{Ni} / \mathrm{Y}-\mathrm{Al}_{2} \mathrm{O}_{3}$ catalysts, it can be seen that the specific surface area and the pore volume decrease with the $\mathrm{Ni}$ loading, and the support $\left(\psi-\mathrm{Al}_{2} \mathrm{O}_{3}\right)$ has the highest specific surface area and pore volume of $94 \mathrm{~m}^{2} / \mathrm{g}$ and $0.343 \mathrm{~cm}^{3} / \mathrm{g}$, respectively.

Table 1. Specific surface area and pore structure of packing materials

\begin{tabular}{|l|l|l|l|}
\hline Packing material & $\begin{array}{l}\text { Specific surface area } \\
\left(\mathrm{m}^{2} / \mathrm{g}\right)\end{array}$ & $\begin{array}{l}\text { Pore volume } \\
\left(\mathrm{cm}^{3} / \mathrm{g}\right)\end{array}$ & $\begin{array}{l}\text { Average diameter } \\
(\mathrm{nm})\end{array}$ \\
\hline Glass pellet & $<1$ & - & - \\
\hline $\mathrm{V}-\mathrm{Al}_{2} \mathrm{O}_{3}$ & 94 & 0.343 & 7.3 \\
\hline $3 \mathrm{wt} \% \mathrm{Ni} / \mathrm{\gamma}-\mathrm{Al}_{2} \mathrm{O}_{3}$ & 82 & 0.328 & 8.0 \\
\hline $5 \mathrm{wt} \% \mathrm{Ni} / \mathrm{Y}-\mathrm{Al}_{2} \mathrm{O}_{3}$ & 76 & 0.289 & 7.6 \\
\hline $10 \mathrm{wt} \% \mathrm{Ni} / \mathrm{\gamma}-\mathrm{Al}_{2} \mathrm{O}_{3}$ & 72 & 0.281 & 7.8 \\
\hline
\end{tabular}

The XRD patterns of the $y-\mathrm{Al}_{2} \mathrm{O}_{3}$ and the $\mathrm{Ni} /{ }-\mathrm{Al}_{2} \mathrm{O}_{3}$ catalysts before and after the reduction are shown in Fig.2. The main peaks at $2 \theta=37.3 \circ, 39.5^{\circ}, 45.8^{\circ}$ and $67^{\circ}$ are observed and attributed to $\mathrm{\gamma}-\mathrm{Al}_{2} \mathrm{O}_{3}$. After the calcination of the catalyst precursor, the characteristic peaks of crystalline $\mathrm{NiO}$ can be detected at $2 \theta=37.2 \circ, 43.3 \circ, 62.9 \circ$ and 75.40 in the fresh $\mathrm{Ni} / \mathrm{Y}^{-} \mathrm{Al}_{2} \mathrm{O}_{3}$ catalyst. When $\mathrm{Ni} / \mathrm{Y}^{-}-\mathrm{Al}_{2} \mathrm{O}_{3}$ catalyst was reduced at $400{ }^{\circ} \mathrm{C}$, it was evident that the peaks for $\mathrm{NiO}$ crystallites disappeared from the pattern and the new peaks were found at $2 \theta=44.3 \circ, 51.60$ and $76.3^{\circ}$, which are ascribed to the formation of metallic Ni.

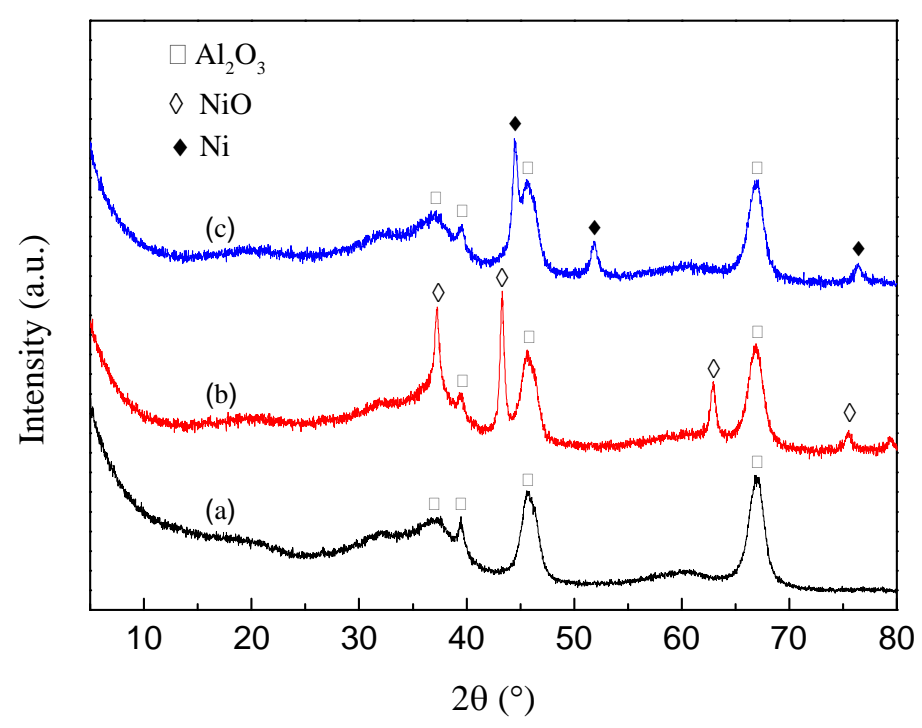

Fig.2. XRD patterns of (a) the support; (b) $10 \mathrm{wt} \% \mathrm{Ni} / \mathrm{\gamma}-\mathrm{Al}_{2} \mathrm{O}_{3}$ before reduction; (c) $10 \mathrm{wt} \% \mathrm{Ni} / \mathrm{\gamma}-\mathrm{Al}_{2} \mathrm{O}_{3}$ after reduction

Fig. 3 shows the TPR curves of $\mathrm{Ni} / \mathrm{Y}-\mathrm{Al}_{2} \mathrm{O}_{3}$ catalysts with different $\mathrm{Ni}$ loading ( $3 \mathrm{wt} . \%, 5$ wt.\% and 10 wt.\%). There 
mainly exist the reduction peaks of $\mathrm{Ni}_{2} \mathrm{O}_{3}\left(350^{\circ} \mathrm{C}-400^{\circ} \mathrm{C}\right)[27,28]$ and $\mathrm{NiO}\left(400^{\circ} \mathrm{C}-900^{\circ} \mathrm{C}\right)[27-29]$. The reduction peaks of $379^{\circ} \mathrm{C}(3 \mathrm{wt} . \% \mathrm{Ni}), 366^{\circ} \mathrm{C}(5 \mathrm{wt} . \% \mathrm{Ni})$ and $368^{\circ} \mathrm{C}(10 \mathrm{wt} . \% \mathrm{Ni})$ are assigned to the reduction of $\mathrm{Ni}_{2} \mathrm{O}_{3}$ species. Clearly, as the $\mathrm{Ni}$ loading increases, the amount of $\mathrm{Ni}_{2} \mathrm{O}_{3}$ species gradually decreases, while the amount of $\mathrm{NiO}$ species gradually increases. The reducible $\mathrm{NiO}$ species can be divided into four types: $\alpha, \beta 1, \beta 2, \gamma[29]$. As shown in Fig.3, the $3 w t . \% \mathrm{Ni} / \gamma^{-}$ $\mathrm{Al}_{2} \mathrm{O}_{3}$ has four reduction peaks in the range of $400^{\circ} \mathrm{C}-900^{\circ} \mathrm{C}$. The peak located at $464^{\circ} \mathrm{C}$ is assigned to $\alpha$-type NiO species, which are free nickel oxides species and have a weak interaction with the $\mathrm{Al}_{2} \mathrm{O}_{3}$ support. The $\beta$-type $\mathrm{NiO}$ species has a stronger interaction with the $\mathrm{Al}_{2} \mathrm{O}_{3}$ support than $\alpha$-type $\mathrm{NiO}$ species, and can be divided into $\beta 1$-type and $\beta 2$-type. The peaks at $611^{\circ} \mathrm{C}$ and $696^{\circ} \mathrm{C}$ could be attributed to the reduction of $\beta 1$-type and $\beta 2$-type NiO species, respectively. The high-temperature reduction peak $\left(815^{\circ} \mathrm{C}\right)$ is assigned to $\gamma$-type $\mathrm{NiO}$ species, which are ascribed to the stable nickel aluminate with a spinel structure. When the $\mathrm{Ni}$ loading increased to $10 \mathrm{wt} . \%$, it can be observed that the reduction peaks of $\alpha$-type, $\beta 1$-type and $\beta 2$-type $\mathrm{NiO}$ species shifted to lower temperatures, from $464^{\circ} \mathrm{C}, 611^{\circ} \mathrm{C}$ and $696^{\circ} \mathrm{C}$ to $436^{\circ} \mathrm{C}$, $494^{\circ} \mathrm{C}$ and $624^{\circ} \mathrm{C}$, respectively. This indicates that the interaction between NiO species and the support becomes weaker with the increase of the $\mathrm{Ni}$ loading in $\mathrm{Ni} / \mathrm{Y}-\mathrm{Al}_{2} \mathrm{O}_{3}$ catalysts.

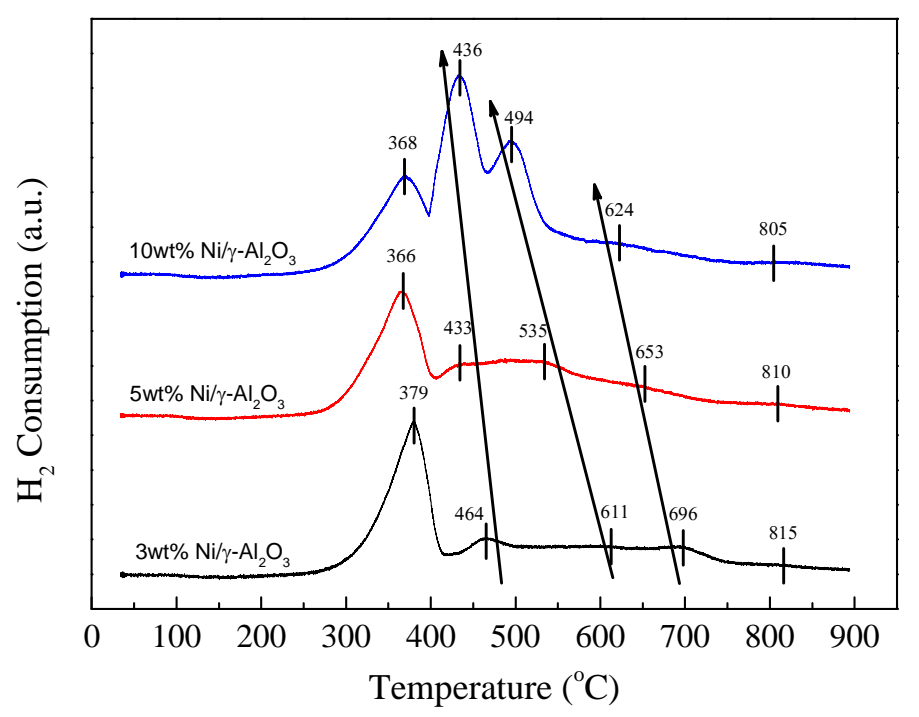

Fig.3 TPR curves of $\mathrm{Ni} / \mathrm{Y}-\mathrm{Al}_{2} \mathrm{O}_{3}$ catalysts with different $\mathrm{Ni}$ loading

\subsection{Effect of carrier gas and packing material}

The removal of toluene was carried out in the DBD reactor with glass pellets and $\gamma-\mathrm{Al}_{2} \mathrm{O}_{3}$ pellets as the packing material, respectively. Fig.4 shows that the removal efficiency of toluene as a function of the specific energy input (SEI) of the plasma discharge in two different carrier gases - fuel gas and $\mathrm{N}_{2}$. Obviously, the toluene removal efficiency in the DBD reactor increases with SEI regardless of the differences of packing materials and carrier gases. In the case of $\mathrm{N}_{2}$ atmosphere, the toluene removal efficiency of $\mathrm{y}^{-\mathrm{Al}_{2} \mathrm{O}_{3}}$ pellets reactor increased from $41.6 \%$ to $74.6 \%$ within the 
SEI range of 206-810 J/L, while for the glass pellets reactor it was $13.6 \%-59.2 \%$ within the SEI of $217-862 \mathrm{~J} / \mathrm{L}$. For the fuel gas atmosphere, the toluene removal efficiency of the glass pellets reactor increased from $7.6 \%$ to $33.5 \%$ with the increase of $\mathrm{SEl}$ from $181 \mathrm{~J} / \mathrm{L}$ to $716 \mathrm{~J} / \mathrm{L}$. As for the $\mathrm{\gamma}-\mathrm{Al}_{2} \mathrm{O}_{3}$ pellets reactor, the toluene removal efficiency varied from $28.3 \%$ to $56.7 \%$ when SEl changed from $202 \mathrm{~J} / \mathrm{L}$ to $826 \mathrm{~J} / \mathrm{L}$. The presence of the packing material in the discharge zone enhances the electric filed intensity especially at the contact positions between pellets and, shifts the discharge type to a combination of micro-discharges in void spaces and surface discharge on the pellets surface [30, 31]. Higher SEI means more gas breakdowns and energetic electrons generated at the pellets surface and in void spaces during single discharge period, which is favorable to the removal of toluene in the DBD plasma reactor [26].

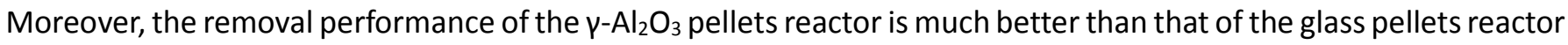
in $\mathrm{N}_{2}$ atmosphere, as shown in Fig.4. At the SEl of $800 \mathrm{~J} / \mathrm{L}$, compared to the toluene removal efficiency of $55 \%$ in the glass pellets reactor, the toluene removal efficiency was elevated up to $74 \%$ when using $\mathrm{\gamma}-\mathrm{Al}_{2} \mathrm{O}_{3}$ pellets as the packing material. In addition, a similar phenomenon was also observed in the fuel gas atmosphere. For example, at $700 \mathrm{~J} / \mathrm{L}$, the toluene removal efficiency was $33 \%$ and $53 \%$ for the glass pellets reactor and $\psi-\mathrm{Al}_{2} \mathrm{O}_{3}$ pellets reactor, respectively. The phenomenon is attributed to the different properties of the two packing materials, such as permittivity, specific surface area and pore structure. Zheng et al. [26] found that the packing materials with higher permittivity could store more energy in a single discharge period, which can accelerate the plasma-chemical process and obtain a better chemical performance in a packed-bed DBD reactor. The $\mathrm{y}-\mathrm{Al}_{2} \mathrm{O}_{3}$ pellets possess a higher permittivity than the glass pellets. In addition, larger specific surface area and pore volume can absorb more toluene molecules and prolong the residence time, which increases the effective collisions between toluene molecules and reactive species generated in the plasma process, resulting in a better removal performance. As shown in Table 1, the specific surface area and pore volume of the $\mathrm{\gamma}-\mathrm{Al}_{2} \mathrm{O}_{3}$ pellets were much larger than those of the glass pellets. Therefore, the reactor packed with the $\mathrm{Y}-\mathrm{Al}_{2} \mathrm{O}_{3}$ pellets achieved a higher toluene removal efficiency in the $\mathrm{DBD}$ plasma reactor. 


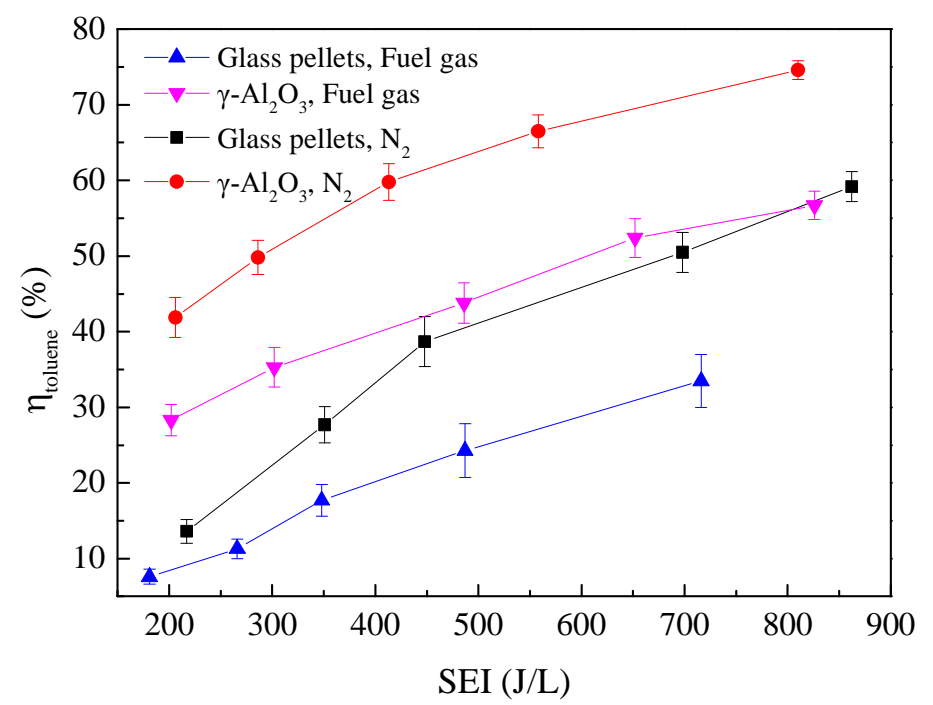

Fig.4. Effect of carrier gas on the toluene removal efficiency as a function of specific energy input in plasma process using glass pellets and $\mathrm{y}-\mathrm{Al}_{2} \mathrm{O}_{3}$ pellets as packing materials (Reaction conditions: total gas flow rate $=0.06 \mathrm{~m}^{3} / \mathrm{h}$, reaction temperature $=200{ }^{\circ} \mathrm{C}$, toluene concentration $=600 \mathrm{ppmv}$ )

Furthermore, it is worth noting that the toluene removal efficiency in the fuel gas atmosphere was significantly lower

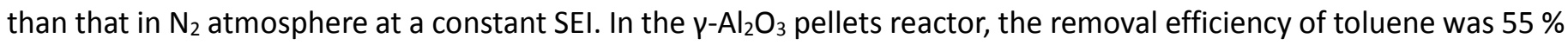
in the fuel gas atmosphere at the SEI of $800 \mathrm{~J} / \mathrm{L}$, while the toluene removal efficiency of $74 \%$ was achieved in $\mathrm{N}_{2}$ atmosphere under the same SEI condition. Previous studies showed that the reaction of tar molecules with the excited $\mathrm{N}_{2}$ molecules was of great importance in the cleaning process due to its high reaction rate [32, 33]. In the fuel gas plasma, the addition of such gases as $\mathrm{CO}, \mathrm{CO}_{2}, \mathrm{H}_{2}$ and $\mathrm{CH}_{4}$ to $\mathrm{N}_{2}$ offers extra reactive species like $\mathrm{O}$ radicals, $\mathrm{H}$ radicals and $\mathrm{CH}_{3}$ radicals, which provide additional channels for toluene removal. However, because of the low reaction rate of tar molecules with the extra reactive species as well as the existence of terminating species for excited $\mathrm{N}_{2}$ molecules in the fuel gas [32], the removal process in the fuel gas atmosphere was not as effective as that in pure $\mathrm{N}_{2}$ atmosphere. As a result, more energy is required to achieve a desired removal performance in a fuel gas atmosphere.

\subsection{Effect of reaction temperature}

The reaction temperature is a very important factor in a plasma process and can affect both the performance of the chemical reactions and the physical properties of the discharge. Previous studies have found increasing temperature enhances the destruction efficiency of volatile organic compounds and decreases energy consumption in plasma processes $[34,35]$. The effects of the reaction temperature on the toluene removal in the packed-bed DBD reactor coupled with different packing materials are shown in Fig.5. It can be seen from Fig.5 that the removal efficiency of 
toluene has differing dependences on the reaction temperature with two packing materials. For both packing materials, the toluene removal efficiency decreased with the temperature at the lower temperature range of $200-250{ }^{\circ} \mathrm{C}$. Increasing temperature exerts negative effect on the permittivity of dielectric medium and packing materials, which causes the decrease of plasma intensity [18]. Thus, the toluene removal efficiency decreases with the increase of temperature at the lower temperature range. At higher temperatures $\left(250-400^{\circ} \mathrm{C}\right)$, the observed differing impacts of temperature on the toluene removal efficiency means different reaction mechanisms in the plasma processes with different packing materials.

In the case of the glass pellets reactor, the toluene removal efficiency reached the minimum value of $13.9 \%$ at $250^{\circ} \mathrm{C}$, and gradually increased to $24 \%$ when the temperature was increased from $250{ }^{\circ} \mathrm{C}$ to $400{ }^{\circ} \mathrm{C}$. As the glass pellets have no catalytic activity, the removal of toluene depends on the balance between the decrease of plasma intensity and the increase of removal reaction rate with rising temperature. The small increase in the toluene removal efficiency after the reaction temperature reached $300{ }^{\circ} \mathrm{C}$ shown in Fig. 5 indicates the positive effect induced by increasing reaction

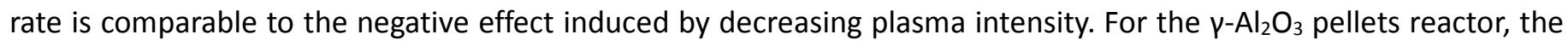
removal efficiency continued to decline with temperature, from $34.3 \%$ at $250{ }^{\circ} \mathrm{C}$ to $11.2 \%$ at $400{ }^{\circ} \mathrm{C}$. This indicates the removal behavior of the $\mathrm{y}-\mathrm{Al}_{2} \mathrm{O}_{3}$ pellets reactor is different from that of the glass pellets reactor. The observed lower toluene removal efficiency at higher temperatures was due to the recombination of the dissociated fragments to

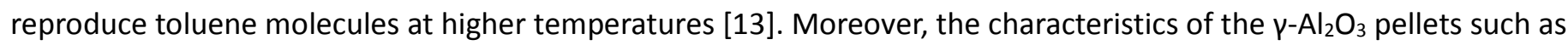
catalytic activity and adsorption properties might be beneficial for the recombination. Possible routes for the recombination of the dissociated fragments are shown in Reactions (6-8) [15]:

$\mathrm{H}+\mathrm{C}_{7} \mathrm{H}_{7} \rightarrow \mathrm{C}_{7} \mathrm{H}_{8}$

$\mathrm{CH}_{3}+\mathrm{C}_{5} \mathrm{H}_{5} \rightarrow \mathrm{C}_{7} \mathrm{H}_{8}$

$\mathrm{C}_{2} \mathrm{H}_{2}+\mathrm{C}_{5} \mathrm{H}_{6} \rightarrow \mathrm{C}_{7} \mathrm{H}_{8}$

In this case, with the increase of temperature, decreasing plasma intensity as well as weakening destruction reaction rate induced by the recombination reactions led to the decrease in the toluene removal efficiency. 


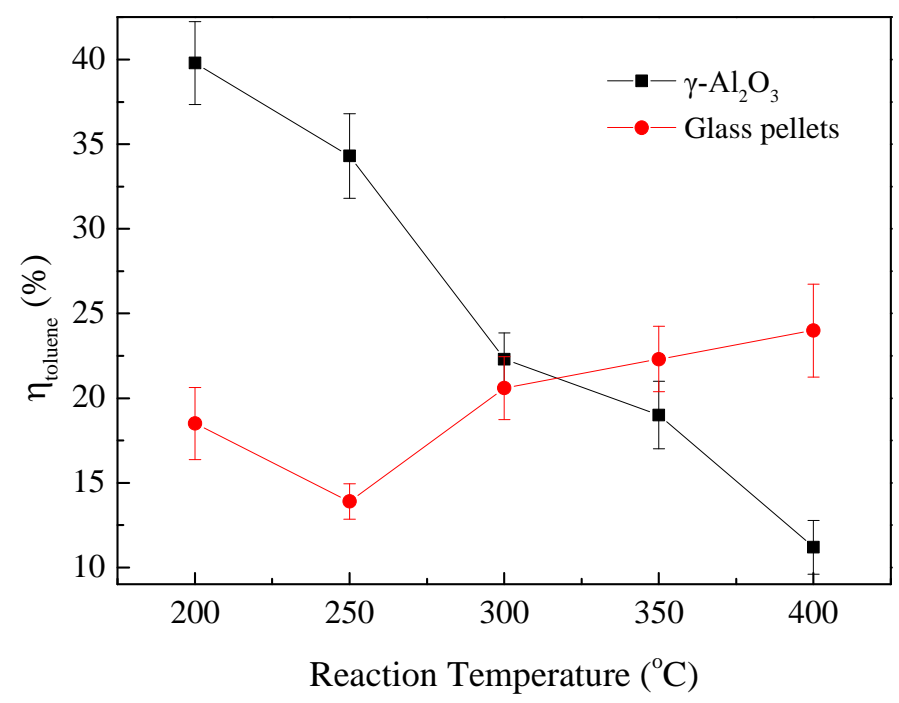

Fig.5. Effect of reaction temperature on the toluene removal efficiency in plasma process using glass pellets and $\gamma^{-}$ $\mathrm{Al}_{2} \mathrm{O}_{3}$ pellets as packing materials (Reaction conditions: total gas flow rate $=0.06 \mathrm{~m}^{3} / \mathrm{h}$, toluene concentration $=600$ ppmv, specific energy input $=\sim 350 \mathrm{~J} / \mathrm{L}$, carrier gas: fuel gas)

These results indicate that the combination of DBD plasma with the glass pellets or the $\mathrm{\gamma}-\mathrm{Al}_{2} \mathrm{O}_{3}$ pellets cannot effectively remove toluene in the fuel gas atmosphere even with the processes being operated at high temperatures. This is mainly attributed to the low or no catalytic activity of the glass and $y-\mathrm{Al}_{2} \mathrm{O}_{3}$ pellets for tar destruction.

Nickel-based catalysts have been widely applied for tar destruction due to their high activity, abundance and low price [8]. In this work, the Ni-impregnated $\mathrm{y}-\mathrm{Al}_{2} \mathrm{O}_{3}$ as a packing material coupled with $\mathrm{DBD}$ plasma was conducted to destruct toluene in the fuel gas atmosphere. In addition, the destruction of toluene using $\mathrm{Ni} / \mathrm{\gamma}-\mathrm{Al}_{2} \mathrm{O}_{3}$ catalyst alone was conducted for comparison. In a plasma-catalysis process, due to different destruction mechanisms, the temperature dependence curve of pollutant destruction can generally be split into two different parts [36,37]. At low temperatures, the pollutant destruction is dominated by the plasma gas phase chemistry and has a small temperature dependence. When the temperature is above a threshold value, the thermal activation of the catalyst becomes to be important and pollution destruction shows a strong dependence on temperature. As shown in Fig.6, the temperature dependence curve of toluene removal is consistent with above explanation. When the temperature was below $300^{\circ} \mathrm{C}$, less than $40 \%$ removal efficiency of toluene was achieved and the removal efficiency decreased with temperature because of the decreasing plasma intensity. Above $300^{\circ} \mathrm{C}$, the toluene removal efficiency significantly increased with temperature. At $400{ }^{\circ} \mathrm{C}$, compared to the case of $\mathrm{Ni} / \mathrm{Y}-\mathrm{Al}_{2} \mathrm{O}_{3}$ catalyst alone, the combination of $\mathrm{Ni} / \mathrm{Y}-\mathrm{Al}_{2} \mathrm{O}_{3}$ catalyst and $\mathrm{DBD}$ plasma significantly enhanced the toluene removal efficiency, reaching $91.7 \%$ from $32.7 \%$ which was achieved with the catalyst alone case. As mentioned above, the combination of plasma and catalyst has the potential to generate 
synergetic effect. The synergetic effect can be confirmed if the removal performance achieved with plasma-catalysis is better than the simple sum of those using plasma alone and catalysis alone [19]. In this study, the toluene removal using glass pellets as the packing material can be regarded as the destruction achieved by plasma alone because of no catalytic activity of glass pellets. As shown in Fig.6, at $400{ }^{\circ} \mathrm{C}$, the toluene removal efficiency of $91.7 \%$ was obtained in the plasma-catalytic process, which is much higher than the sum of those using DBD plasma alone and $\mathrm{Ni} / \mathrm{Y}-\mathrm{Al}_{2} \mathrm{O}_{3}$ catalyst alone, hence indicating the occurrence of the synergetic effect under this condition $\left(400{ }^{\circ} \mathrm{C}\right)$. However, no obvious synergetic effect was observed when the temperature was at $300-350^{\circ} \mathrm{C}$. Within the temperature range of $200-250{ }^{\circ} \mathrm{C}$, the toluene removal efficiency in the plasma-catalytic process was higher than the sum of those using plasma alone and catalyst alone, however, this was mainly attributed to the difference between the packing materials (glass pellets and $\mathrm{Ni} / \mathrm{Y}-\mathrm{Al}_{2} \mathrm{O}_{3}$ catalyst) rather than the synergetic effect. Obviously, the synergetic effect has a close relationship with temperature. At low temperatures, no obvious synergetic effect is obtained due to low catalytic activity. With the increase of temperature, the synergetic effect is achieved when the temperature is above a threshold value, where both plasma process and catalytic activity are important.

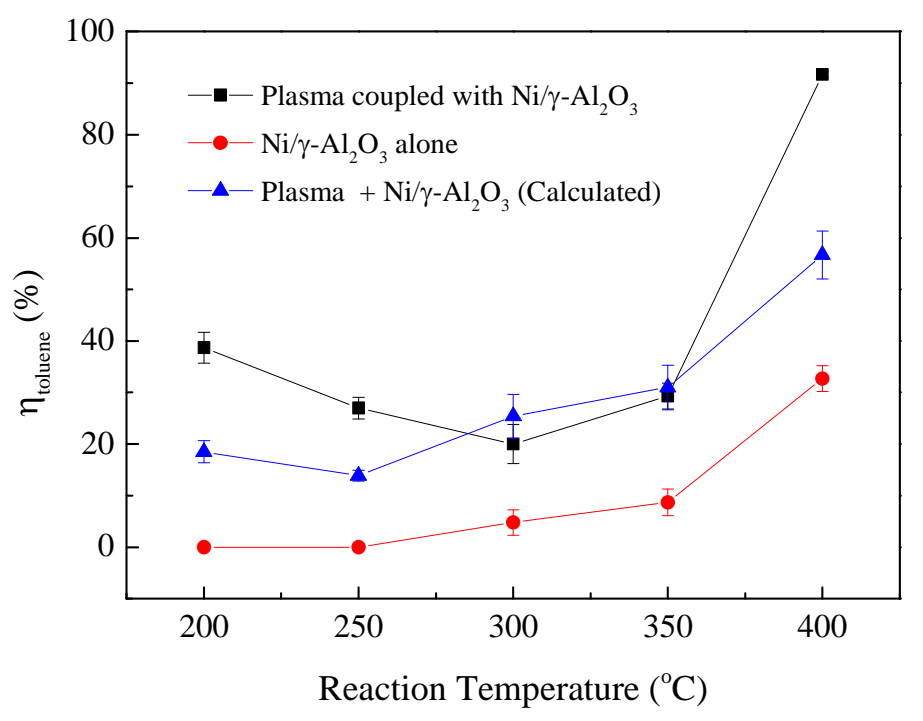

Fig.6. Effect of reaction temperature on the toluene removal efficiency using DBD coupled with $\mathrm{Ni} / \mathrm{Y}^{-}-\mathrm{Al}_{2} \mathrm{O}_{3}$ and $\mathrm{Ni} / \mathrm{Y}^{-}$ $\mathrm{Al}_{2} \mathrm{O}_{3}$ catalyst alone (Reaction conditions: total gas flow rate $=0.06 \mathrm{~m}^{3} / \mathrm{h}$, toluene concentration $=600 \mathrm{ppmv}$, specific energy input $=\sim 350 \mathrm{~J} / \mathrm{L}$, Ni loading $=5 \mathrm{wt} \%$, carrier gas: fuel gas)

In the experiments, the high concentration of benzene was detected at the outlet when the plasma-catalytic process was operated at high temperatures. Benzene is a typical compound of tars, and it is often used as a surrogate tar in previous researches due to its high thermal stability and simple structure [5]. In tar removal processes, gaseous products with lighter molecular weights such as $\mathrm{H}_{2}, \mathrm{CH}_{4}$, and $\mathrm{C}_{2} \mathrm{H}_{2}$ are the desired products but benzene is not a desired 
product. As described by equation (2), the tar removal efficiency in this work is defined as the ratio of the removed amount of tars (toluene and benzene) to the initial tar concentration (toluene concentration at the inlet), and hence it evaluates the ability of converting toluene into light gaseous products in the plasma-catalytic process. Fig.7 shows the selectivity of benzene and the tar removal efficiency in the plasma-catalytic process as a function of the reaction temperature. It can be seen that the temperature has great effects on both the selectivity of benzene and the tar removal efficiency. The selectivity of benzene increased with temperature from $200{ }^{\circ} \mathrm{C}$ to $350{ }^{\circ} \mathrm{C}$, reaching the maximum value of $68.3 \%$, and then notably decreased to $28.7 \%$ at $400{ }^{\circ} \mathrm{C}$. The thermal activation of catalyst plays a crucial role in the production of benzene. With the temperature rising, the increasing catalytic activity is beneficial to benzene production in the toluene removal process, improving the selectivity of benzene. The high catalytic activity at temperatures higher than $350{ }^{\circ} \mathrm{C}$ can further crack benzene into lighter products, which causes the decrease of the selectivity of benzene. For the tar removal efficiency, it declined from $35 \%$ to $6 \%$ as the temperature was raised from $200{ }^{\circ} \mathrm{C}$ to $350{ }^{\circ} \mathrm{C}$, and then significantly increased to $61 \%$ at $400{ }^{\circ} \mathrm{C}$. At low temperatures, the decreasing toluene removal efficiency causes the decrease of tar removal efficiency with the rising temperature. At $350^{\circ} \mathrm{C}$, although the toluene removal efficiency slightly increased to 29.3 \% (Fig.6), a large amount of benzene generated in plasma-catalytic process led to the continuous decreasing of tar removal efficiency. At temperatures above $350^{\circ} \mathrm{C}$, the synergetic effect of plasma and catalyst significantly improves the toluene removal efficiency, and the decreasing selectivity of benzene means toluene is inclined to be cracked into lighter products at such a high temperature. Thus, the highest tar removal efficiency was achieved at $400{ }^{\circ} \mathrm{C}$. Higher reaction temperatures have not been used in this study due to the temperature limitation of the DBD reactor, however, it can be deduced from the above results that a higher tar removal efficiency and a lower selectivity of benzene can be obtained if the reaction temperature is increased further above $400{ }^{\circ} \mathrm{C}$.

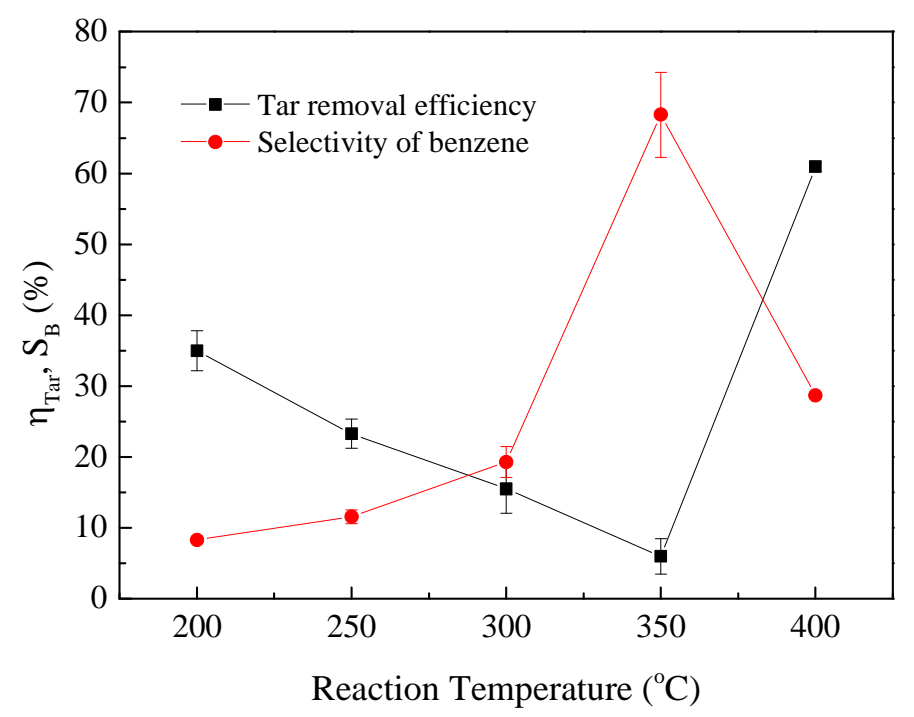


Fig.7. Effects of reaction temperature on the selectivity of benzene and tar removal efficiency in plasma-catalytic process (Reaction conditions: total gas flow rate $=0.06 \mathrm{~m}^{3} / \mathrm{h}$, toluene concentration $=600 \mathrm{ppmv}$, specific energy input $=\sim 350 \mathrm{~J} / \mathrm{L}$, Ni loading $=5 \mathrm{wt} \%$, carrier gas: fuel gas)

\subsection{Effect of Ni loading}

The effect of Ni loading on the toluene removal efficiency at different reaction temperatures is shown in Fig.8. Clearly, there is a little difference in the toluene removal behavior of catalysts with different Ni loadings ( $3 \mathrm{wt} \%, 5 \mathrm{wt} \%$ and 10 wt\%). The toluene removal efficiency with $3 \mathrm{wt} \% \mathrm{Ni} / \mathrm{Y}-\mathrm{Al}_{2} \mathrm{O}_{3}$ and $10 \mathrm{wt} \% \mathrm{Ni} / \mathrm{Y}-\mathrm{Al}_{2} \mathrm{O}_{3}$ decreased to the same minimum value of $17 \%$ at $300{ }^{\circ} \mathrm{C}$ after the temperature was increased from $200{ }^{\circ} \mathrm{C}$, and then increased to $80.2 \%$ and $100 \%$ at $400{ }^{\circ} \mathrm{C}$, respectively. Moreover, it is worth noting that the toluene removal efficiency had an order of $3 \mathrm{wt} \%>5 \mathrm{wt} \%>$ $10 \mathrm{wt} \%$ below $300^{\circ} \mathrm{C}$, while a reverse phenomenon was found when the temperature was above $300^{\circ} \mathrm{C}$. As suggested by the TPR results, the higher Ni loading weakens the interaction between $\mathrm{NiO}$ species and the support, which increases the fraction of reducible $\mathrm{NiO}$ at $400^{\circ} \mathrm{C}$, consequently forming more Ni particles on the catalyst surface. Jo et al. [38] found that the presence of conductive particles on the surface of catalyst reduced the overall electric field in DBD plasma, resulting in the decrease of plasma intensity. Moreover, as mentioned above, the removal of toluene is dominated by the plasma chemical reactions and has a dependence on plasma intensity at low temperatures. Therefore, it can be assumed that a higher loading of $\mathrm{Ni}$ exerts greater negative effect on plasma intensity when compared to a lower Ni loading, leading to a lower removal performance with higher Ni loading catalyst at low temperatures. However, at high temperatures, the catalytic activity plays an important role in the destruction of toluene. The higher Ni loading of catalyst means more active sites formed on the catalyst surface, which is conducive to the toluene removal. Therefore, a higher toluene removal efficiency is obtained for the catalyst with a higher $\mathrm{Ni}$ loading at high temperatures. 


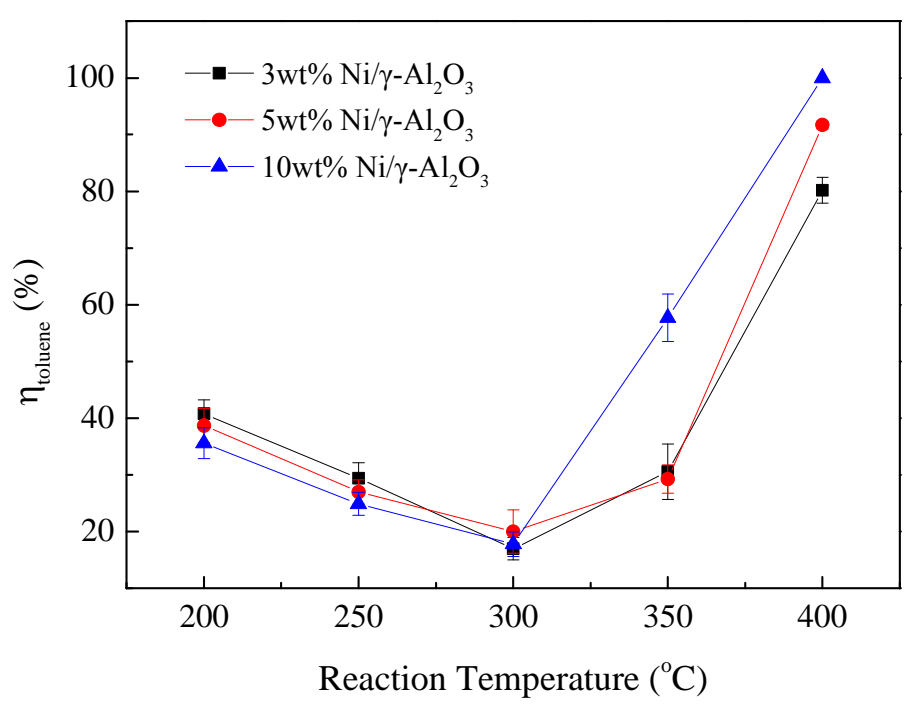

Fig.8. Effect of Ni loading on toluene removal efficiency as a function of reaction temperature in plasma-catalytic process (Reaction conditions: total gas flow rate $=0.06 \mathrm{~m}^{3} / \mathrm{h}$, toluene concentration $=600 \mathrm{ppmv}$, specific energy input $=\sim 350 \mathrm{~J} / \mathrm{L}$, carrier gas: fuel gas)

Fig.9 presents the effect of $\mathrm{Ni}$ loading on the selectivity of benzene and tar removal efficiency at varying reaction temperatures. The selectivity of benzene for $10 \mathrm{wt} \% \mathrm{Ni}$ loading experienced an increase with rising temperature, reaching the peak value of $66.3 \%$, and then significantly decreased as the temperature was above $350{ }^{\circ} \mathrm{C}$, which is similar to that of $5 \mathrm{wt} \% \mathrm{Ni}$ loading (Fig.7). Besides, the increasing and decreasing rates of $10 \mathrm{wt} \% \mathrm{Ni}$ loading were greater than those of $5 \mathrm{wt} \% \mathrm{Ni}$ loading due to the formation of more active sites on $10 \mathrm{wt} \% \mathrm{Ni} / \mathrm{Y}-\mathrm{Al}_{2} \mathrm{O}_{3}$ surface. However, for the $3 \mathrm{wt} \% \mathrm{Ni}$ loading, the selectivity of benzene increased from $6.6 \%$ to $37.7 \%$ when the temperature increased from $200^{\circ} \mathrm{C}$ to $400^{\circ} \mathrm{C}$. The differing trends observed for $3 \mathrm{wt} \%$ and $10 \mathrm{wt} \% \mathrm{Ni}$ loadings can be explained as follows: the production of benzene was enhanced by the rising temperature, while the $3 \mathrm{wt} \% \mathrm{Ni} / \mathrm{Y}-\mathrm{Al}_{2} \mathrm{O}_{3}$ had not enough active sites to further crack benzene into lighter products, leading to the continuous increase of the selectivity of benzene. In the case of the tar removal efficiency, the catalysts with different $\mathrm{Ni}$ loadings ( $3 \mathrm{wt} \%$ and $10 \mathrm{wt} \%$ ) experienced a decrease and then an increase with increasing temperature, having the same reflection point of $300^{\circ} \mathrm{C}$. Moreover, the tar removal efficiency of the $10 \mathrm{wt} \% \mathrm{Ni}$ loading was 5-10\% lower than that of the $3 \mathrm{wt} \% \mathrm{Ni}$ loading below $350{ }^{\circ} \mathrm{C}$. At $400{ }^{\circ} \mathrm{C}$, the plasma-catalytic process achieved $98 \%$ tar removal efficiency for $10 \mathrm{wt} \% \mathrm{Ni} / \mathrm{\gamma}-\mathrm{Al}_{2} \mathrm{O}_{3}$ whereas only $50 \%$ was obtained for $3 \mathrm{wt} \% \mathrm{Ni} / \mathrm{V}-\mathrm{Al}_{2} \mathrm{O}_{3}$ at this temperature. These results show that higher $\mathrm{Ni}$ loadings and temperatures are beneficial to achieve a higher tar removal efficiency in the plasma-catalytic process. 


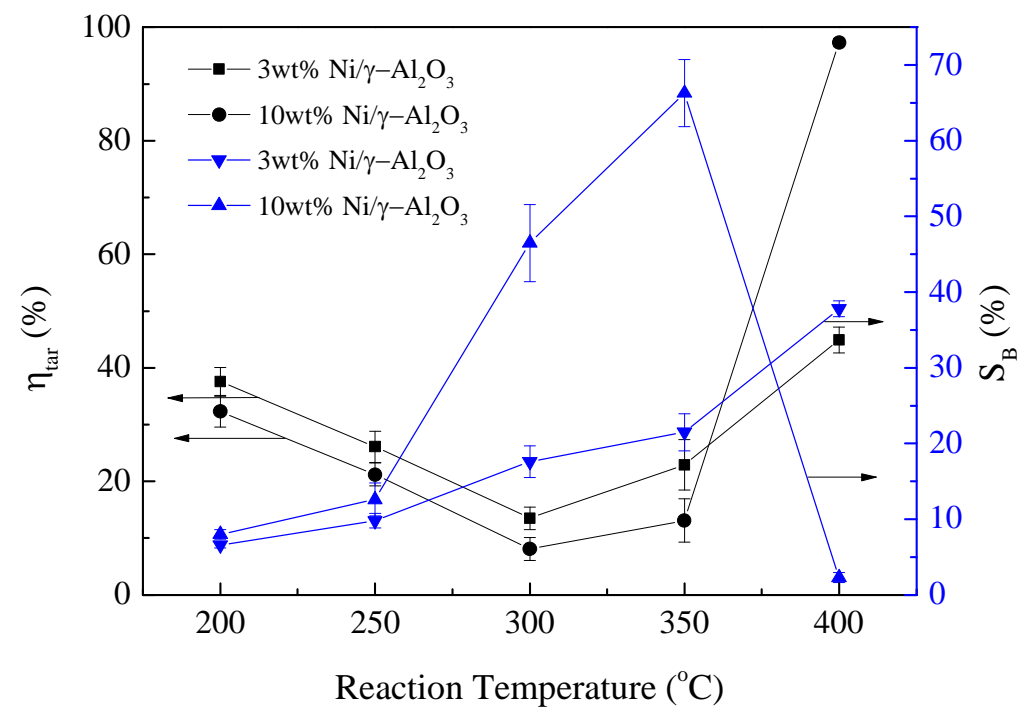

Fig.9. Effect of Ni loading on the selectivity of benzene and tar removal efficiency as a function of reaction temperature in plasma-catalytic process (Reaction conditions: total gas flow rate $=0.06 \mathrm{~m}^{3} / \mathrm{h}$, toluene concentration $=600$ ppmv, specific energy input $=\sim 350 \mathrm{~J} / \mathrm{L}$, carrier gas: fuel gas)

\subsection{Effect of toluene concentration}

The effects of the toluene concentration on the toluene removal efficiency and energy efficiency are presented in Fig.10. The toluene removal efficiency decreased from $92.7 \%$ to $88.1 \%$ when the toluene concentration was increased from 400 ppmv to 1200 ppmv. When the SEl, total gas flow rate and reaction temperature are fixed, the amount of electrons and active species in the plasma should be constant and hence, each toluene molecule shares fewer electrons and active species with an increase in the toluene concentration, resulting in a decrease in the toluene removal efficiency. In addition, the toluene concentration also exerts an important effect on the energy efficiency of toluene removal in the plasma-catalytic process. As shown in Fig.10, the energy efficiency $(\mathrm{E})$ increased linearly from $5.9 \mathrm{~g} / \mathrm{kWh}$ to $16.9 \mathrm{~g} / \mathrm{kWh}$ as the toluene concentration was changed from $400 \mathrm{ppmv}$ to $1200 \mathrm{ppmv}$. 


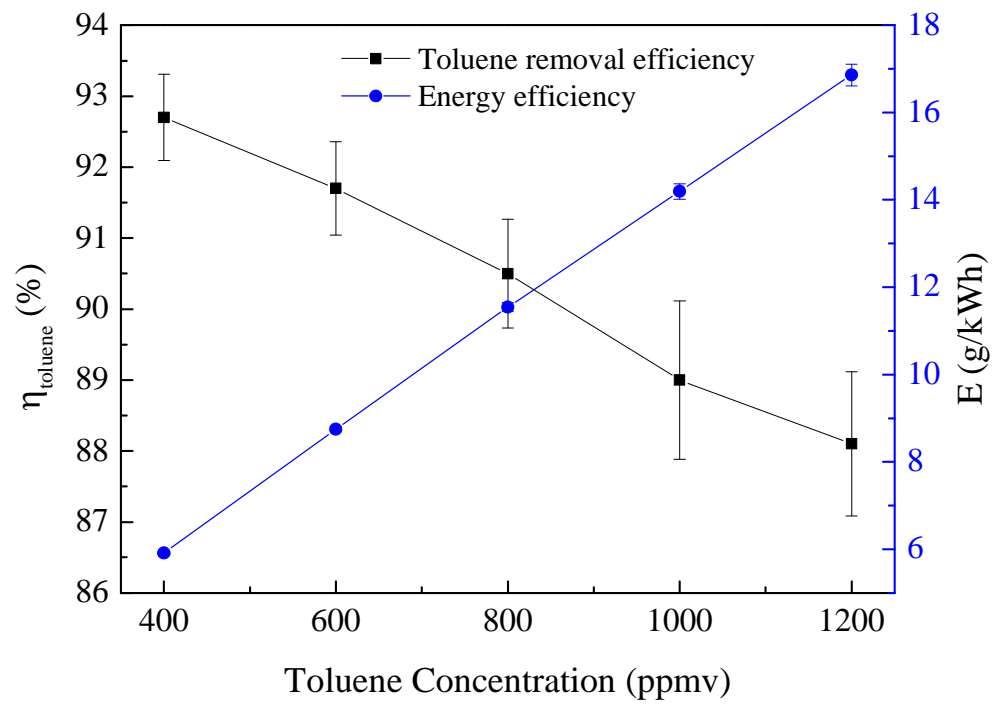

Fig.10. Effect of toluene concentration on toluene removal efficiency and energy efficiency in plasma-catalytic process (Reaction conditions: total gas flow rate $=0.06 \mathrm{~m}^{3} / \mathrm{h}$, reaction temperature $=400{ }^{\circ} \mathrm{C}$, heating power $=8.1 \mathrm{~W}$, specific energy input $=\sim 350 \mathrm{~J} / \mathrm{L}, \mathrm{Ni}$ loading $=5 \mathrm{wt} \%$, carrier gas: fuel gas)

\subsection{The analysis of exhaust gas}

The removal of toluene in the plasma-catalytic reactor with the fuel gas as carrier gas is a very complex process. A variety of reactions are involved in this process, including the reactions of all gas components in the carrier gas and causing the concentration variations of each component in the fuel gas. Fig.11 presents the concentrations of $\mathrm{H}_{2}, \mathrm{CO}$, $\mathrm{CO}_{2}$ and $\mathrm{CH}_{4}$ at the outlet of the reactor as a function of reaction temperature. Clearly, for both the catalyst alone process and the plasma-catalytic process, the gas concentrations at the outlet changed with the reaction temperature. The concentrations of $\mathrm{H}_{2}$ and $\mathrm{CO}$ at the outlet decreased with temperature but a reverse trend was found for $\mathrm{CH}_{4}$ and $\mathrm{CO}_{2}$ in both the plasma-catalytic process and the catalyst alone process. For the plasma-catalytic process, the lowest concentrations of $\mathrm{H}_{2}$ and $\mathrm{CO}, 8.5 \%$ and $12.3 \%$, respectively, were achieved at $400{ }^{\circ} \mathrm{C}$, while the maximum concentrations of $\mathrm{CH}_{4}$ and $\mathrm{CO}_{2}$ of $4.4 \%$ and $15.5 \%$, respectively, were reached at the same temperature (Fig.11a). For the catalyst alone process, the lowest concentrations of $\mathrm{H}_{2}$ and $\mathrm{CO}$ of $9.8 \%$ and $13.6 \%$, respectively, and the maximum concentrations of $\mathrm{CH}_{4}$ and $\mathrm{CO}_{2}$ of $3.5 \%$ and $14.3 \%$, respectively, were achieved at $400{ }^{\circ} \mathrm{C}$ (Fig.11b), In this case, the destruction of toluene could not exert great influence on the content of fuel gas due to the low concentration of toluene. According to the previous studies, the great change of compositions in the fuel gas is ascribed to two kinds of important reactions: methanation reactions and water gas shift reaction $[39,40]$, as shown in Reactions $(9-11)$ : Methanation reactions:

$\mathrm{CO}+3 \mathrm{H}_{2} \rightarrow \mathrm{CH}_{4}+\mathrm{H}_{2} \mathrm{O}$ 
$\mathrm{CO}_{2}+4 \mathrm{H}_{2} \rightarrow \mathrm{CH}_{4}+2 \mathrm{H}_{2} \mathrm{O}$

Water gas shift reaction:

$\mathrm{CO}+\mathrm{H}_{2} \mathrm{O} \rightarrow \mathrm{H}_{2}+\mathrm{CO}_{2}$

It can be seen that methanation consumes $\mathrm{H}_{2}, \mathrm{CO}$ and $\mathrm{CO}_{2}$ and produces $\mathrm{CH}_{4}$, thus significantly affects the concentration of $\mathrm{H}_{2}$ and $\mathrm{CH}_{4}$. Besides, in the methanation process, the methanation of $\mathrm{CO}_{2}$ is completely suppressed as long as $\mathrm{CO}$ remains in the fuel gas [41]. Thus, we can conclude that the $\mathrm{H}_{2}$ consumption is caused predominantly by CO methanation. In addition, the water gas shift reaction causes the further decrease of CO and increases the concentration of $\mathrm{CO}_{2}$. When the temperature was increased from $200{ }^{\circ} \mathrm{C}$ to $400{ }^{\circ} \mathrm{C}$, the methanation rate was accelerated, which enhances the consumption of $\mathrm{CO}$ and $\mathrm{H}_{2}$, correspondingly leading to the rising of the concentrations of $\mathrm{CH}_{4}$ and $\mathrm{CO}_{2}$. Furthermore, by comparing Fig.11a and Fig.11b, it can be seen that the concentration of $\mathrm{CH}_{4}$ in the plasma-catalytic process is higher than that in the catalyst alone process regardless of the reaction temperature. Therefore, the introduction of plasma enhanced the methanation reactions of the fuel gas occurring in the catalytic process

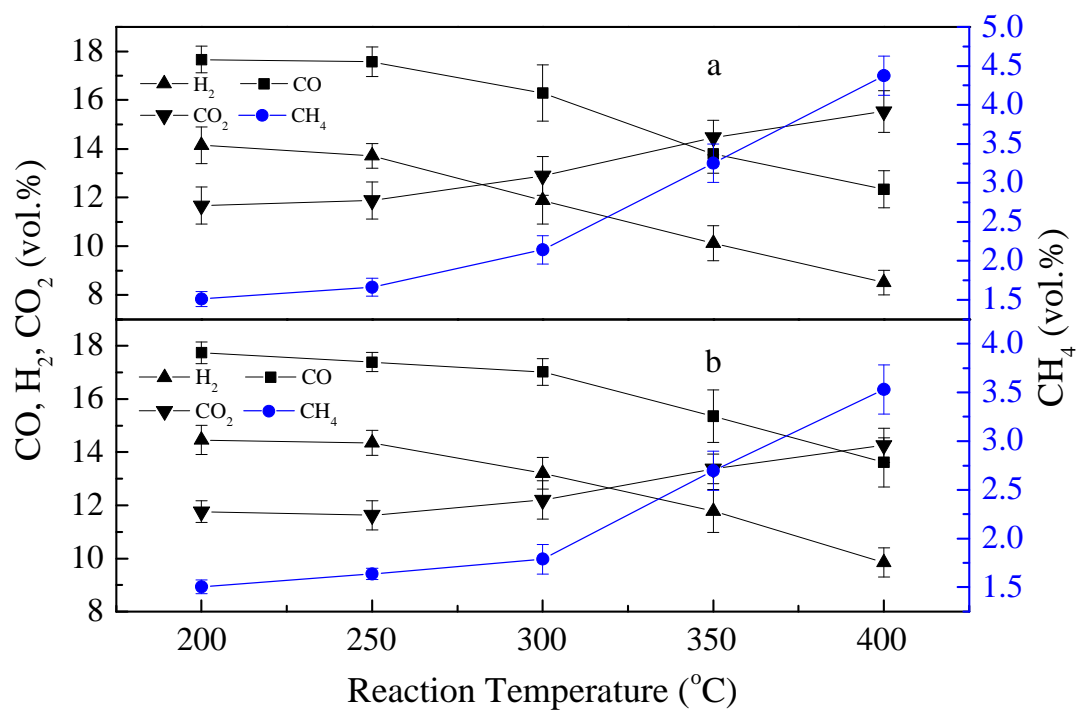

Fig.11. Concentrations of $\mathrm{H}_{2}, \mathrm{CO}, \mathrm{CO}_{2}$ and $\mathrm{CH}_{4}$ at the outlet as a function of reaction temperature in plasma-catalytic process (a) and catalytic alone process (b) (Reaction condition: total gas flow rate $=0.06 \mathrm{~m}^{3} / \mathrm{h}$, toluene concentration $=600$ ppmv, specific energy input $=\sim 350 \mathrm{~J} / \mathrm{L}$, Ni loading $=5 \mathrm{wt} \%$, carrier gas: fuel gas)

The production of substitute natural gas (SNG) through the methanation of bio-syngas has attracted extensive attention recently $[42,43]$. In this work, in addition to the removal of toluene, the methanation of the fuel gas was achieved in the plasma-catalytic process. For instance, at $400{ }^{\circ} \mathrm{C}$, the concentration of $\mathrm{CH}_{4}$ at the outlet was nearly three times higher than that at the inlet, and the corresponding CO conversion was $31.4 \%$. Besides, we found the 
combination of plasma and catalyst could effectively enhance the performance of methanation in the fuel gas, as shown in Fig.11. However, the fuel gas derived from biomass gasification usually has a low $\mathrm{H}_{2} / \mathrm{CO}$ ratio of $0.3-2$ [42], which is too low for good methanation reactions. Moreover, the low $\mathrm{H}_{2} / \mathrm{CO}$ ratio has a negative influence on catalyst lifetime due to the severe carbon deposition on the catalyst surface [40]. In the present study, the $\mathrm{H}_{2} / \mathrm{CO}$ ratio of fuel gas is 0.8 , resulting in the low CO conversion. Moreover, the gradual decrease of toluene removal efficiency was observed after $2 \mathrm{~h}$ of reaction in the plasma-catalytic process at $400{ }^{\circ} \mathrm{C}$, which is believed to be due to the severe carbon deposition. Thus, further efforts need to be applied to enhance the stability of catalyst and improve the performance of methanation in the plasma-catalytic process. For example, by means of $\mathrm{H}_{2} \mathrm{O}$ addition to the fuel gas, the $\mathrm{H}_{2} / \mathrm{CO}$ ratio can be adjusted by water gas shift reaction to an appropriate value, resulting in the decrease of carbon deposition and the improvement of $\mathrm{CO}$ conversion and $\mathrm{CH}_{4}$ selectivity [39].

Two other gaseous products, $\mathrm{C}_{2} \mathrm{H}_{2}$ and $\mathrm{C}_{2} \mathrm{H}_{6}$, were also detected at the outlet of the reactor. The same gaseous products have been found in toluene destruction using gliding arc discharge plasma [14]. Fig.12 shows the concentrations of $\mathrm{C}_{2} \mathrm{H}_{2}$ and $\mathrm{C}_{2} \mathrm{H}_{6}$ at the outlet of the plasma-catalytic reactor and the catalyst alone reactor as a function of reaction temperature. With increasing temperature, the concentration of both $\mathrm{C}_{2} \mathrm{H}_{2}$ and $\mathrm{C}_{2} \mathrm{H}_{6}$ increased at first, reaching the maximum values of $829 \mathrm{ppmv}$ and $215 \mathrm{ppmv}$, respectively, at $300{ }^{\circ} \mathrm{C}$, and then decreased again in the plasma-catalytic process. A similar trend was observed in the catalyst alone process, but the maximum values were obtained at $350{ }^{\circ} \mathrm{C}$ for $\mathrm{C}_{2} \mathrm{H}_{2}$ and $\mathrm{C}_{2} \mathrm{H}_{6} . \mathrm{C}_{2} \mathrm{H}_{2}$ and $\mathrm{C}_{2} \mathrm{H}_{6}$ were not found with the catalyst alone process at $200{ }^{\circ} \mathrm{C}$ but low concentrations of $\mathrm{C}_{2} \mathrm{H}_{2}$ and $\mathrm{C}_{2} \mathrm{H}_{6}$ were detected at the outlet of the plasma-catalytic process. This phenomenon can be attributed to the dissociation of toluene induced by the plasma process. Urashima et al. [44] suggested that the destruction of toluene in the plasma could be subdivided into two kinds of major reactions: abstraction of the methyl group and breaking of benzene ring induced by excited molecules and energetic electrons, as shown in Reactions (1214):

$\mathrm{C}_{7} \mathrm{H}_{8} \rightarrow \mathrm{C}_{6} \mathrm{H}_{5} \mathrm{CH}_{2}+\mathrm{H}$

$\mathrm{C}_{7} \mathrm{H}_{8} \rightarrow \mathrm{C}_{6} \mathrm{H}_{5}+\mathrm{CH}_{3}$

$\mathrm{C}_{7} \mathrm{H}_{8} \rightarrow \mathrm{C}_{5} \mathrm{H}_{6}+\mathrm{C}_{2} \mathrm{H}_{2}$

$\mathrm{C}_{2} \mathrm{H}_{6}$ is formed through the recombination of two $\mathrm{CH}_{3}$ radicals. At high temperatures, the high concentration of $\mathrm{C}_{2} \mathrm{H}_{2}$ and $\mathrm{C}_{2} \mathrm{H}_{6}$ formed in the plasma-catalytic process could not completely ascribed to the dissociation of toluene induced by excited species because of the low tar removal efficiency at this temperature. The high concentration of $\mathrm{C}_{2} \mathrm{H}_{2}$ and $\mathrm{C}_{2} \mathrm{H}_{6}$ at the outlet of the catalyst alone reactor confirms the result (Fig.12). Other reactions in this complex system could also generate $\mathrm{C}_{2} \mathrm{H}_{2}$ and $\mathrm{C}_{2} \mathrm{H}_{6}$ For example, $\mathrm{C}_{2} \mathrm{H}_{2}$ and $\mathrm{C}_{2} \mathrm{H}_{6}$ are the main by-products in dry reforming of methane [19]. 


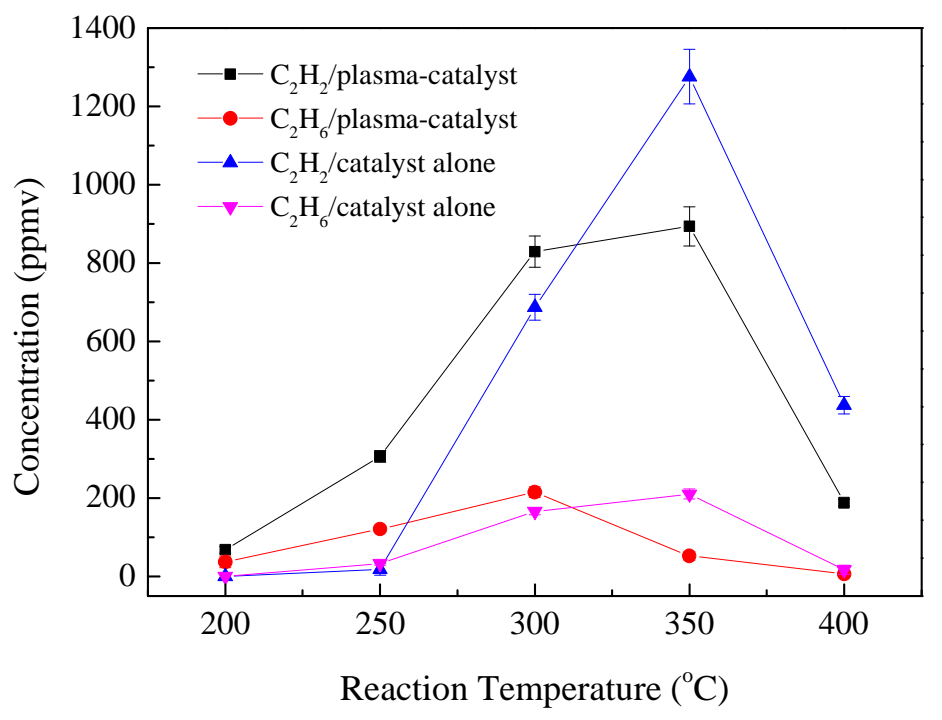

Fig.12. Concentrations of $\mathrm{C}_{2} \mathrm{H}_{2}$ and $\mathrm{C}_{2} \mathrm{H}_{6}$ at the outlet as a function of reaction temperature in plasma-catalytic process and catalytic alone process (Reaction condition: total gas flow rate $=0.06 \mathrm{~m}^{3} / \mathrm{h}$, toluene concentration $=600$ ppmv, specific energy input $=\sim 350 \mathrm{~J} / \mathrm{L}, \mathrm{Ni}$ loading $=5 \mathrm{wt} \%$, carrier gas: fuel gas)

\subsection{Reaction mechanisms}

To understand the reaction mechanisms and pathways of toluene destruction in the plasma-catalytic process, the liquid by-products collected in the hexane solution were qualitatively analyzed by GC-MS, as shown in Table.2. Only six types of organic by-products were detected, which are benzene, ethylbenzene, 1,2-dimethyl-benzene, 1,3- dimethylbenzene, 1-ethyl-3-methyl-benzene and naphthalene. These by-products are all aromatic hydrocarbons and there were no oxygenates detected in the liquid by-products. Benzene, ethylbenzene and naphthalene have also been detected in other toluene destruction processes by other researchers using gliding arc discharge $[14,15]$. It is worth noting that the concentrations of the by-products whose molecular weights are larger than toluene are several orders of magnitude lower than that of toluene, and this means a very small proportion of toluene was converted to highmolecular weight products in the plasma-catalytic process. These by-products are generated from the recombination of intermediate molecular fragments derived from the dissociation of the toluene molecules. As mentioned above, the free radicals such as benzyl $\left(\mathrm{C}_{6} \mathrm{H}_{5} \mathrm{CH}_{2}\right)$, phenyl $\left(\mathrm{C}_{6} \mathrm{H}_{5}\right)$, ethyl $\left(\mathrm{C}_{2} \mathrm{H}_{5}\right)$, methyl $\left(\mathrm{CH}_{3}\right)$ and $\mathrm{H}$ are generated in plasma-catalytic process. In addition, $\mathrm{H}$-abstraction from the benzene ring cannot be completely disregarded although the $\mathrm{C}-\mathrm{H}$ bonds in the benzene ring are stronger than that in the methyl group. Thus, the methyl-phenyl $\left(\mathrm{C}_{6} \mathrm{H}_{4} \mathrm{CH}_{3}\right)$ radicals are also obtained in the toluene removal process. The by-products are obtained by the recombination of these free radicals.

Table.2. Product identified in liquid sample by GC-MS 


(1,3-dimethyl-benzene

The possible reaction pathways of toluene removal in the plasma-catalytic process are schematically shown in Fig.13. The $\mathrm{C}-\mathrm{H}$ bond in methyl of toluene can be easily broken by excited species, energetic electrons and catalytic effect to produce benzyl radicals $[15,45]$. The recombination of benzyl and methyl radicals produces ethylbenzene. In addition, the methyl-phenyl generated from $\mathrm{H}$-abstraction from benzene ring of toluene recombine with methyl and ethyl radicals to generate 1,2-dimethyl-benzene (1,3-dimethyl-benzene) and 1-ethyl-3-methyl-benzene, respectively. Toluene can be ruptured by the dissociation of C-C bonds between methyl and benzene ring, generating phenyl radicals. As shown in Fig.13, phenyl radicals react with $\mathrm{H}$ radicals to form benzene, and benzene is further decomposed to form $\mathrm{H}_{2}$ and $\mathrm{CO}$. At the same time, the addition of acetylene to phenyl radicals produces phenylacetylene, which is followed by further reaction with acetylene to form naphthalene [46]. Moreover, the other routes of toluene removal may be induced by the dissociation of $\mathrm{C}-\mathrm{C}$ bonds of the benzene ring, leading to the formation of bi-radical $\mathrm{HC}=\mathrm{CH}$ and methylcyclobutadiene, and eventually producing acetylene, $\mathrm{CO}$ and $\mathrm{H}_{2}$. 


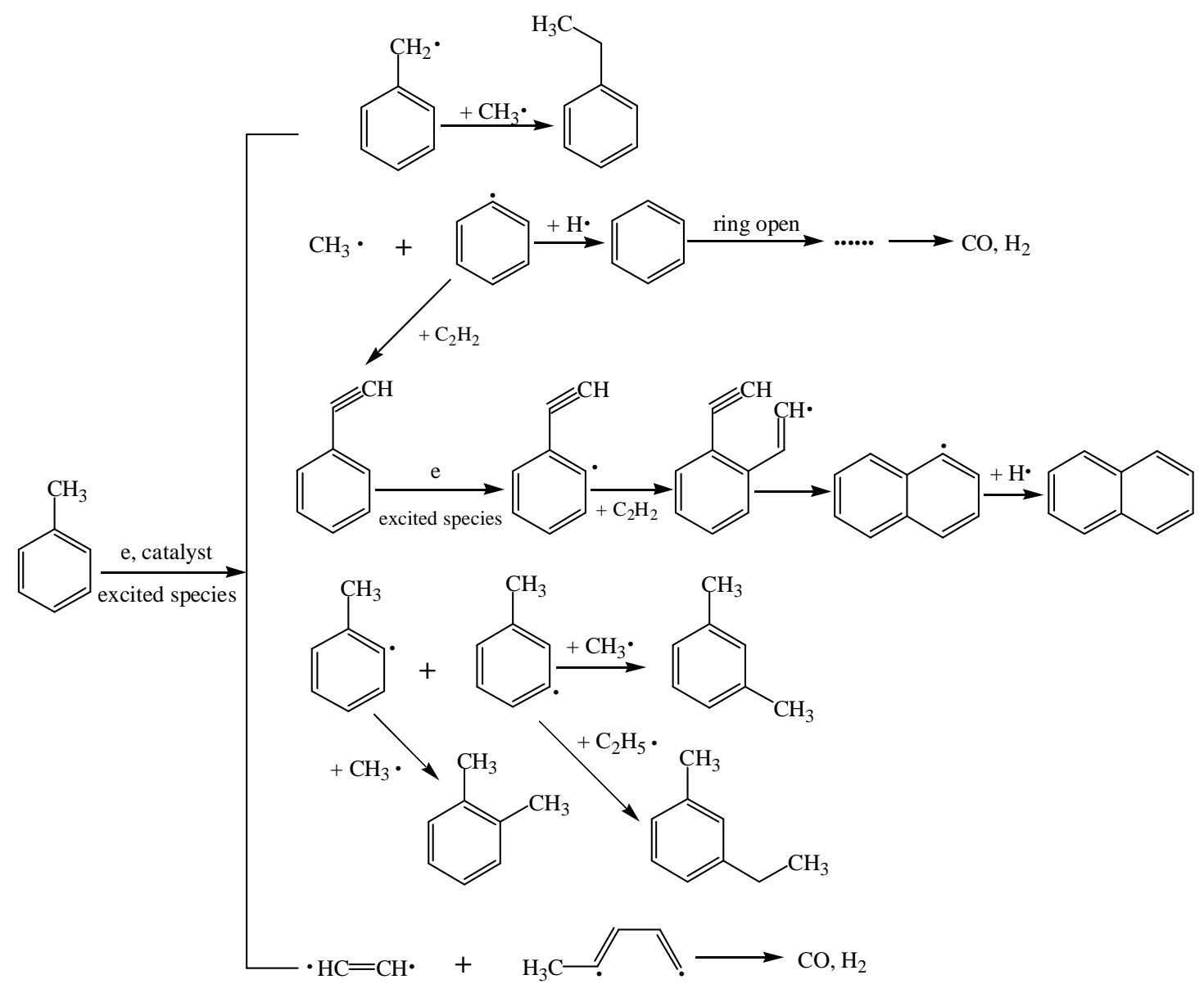

Fig.13. Possible reaction pathways for toluene destruction in the plasma-catalytic process

\section{Conclusions}

In this study, the removal of toluene in the fuel gas has been carried out using a DBD reactor combined with different packing materials, and the effects of carrier gas, reaction temperature, Ni loading and toluene concentration on the toluene removal have been investigated. Moreover, the analysis of the exhaust gas and liquid products are conducted. The conclusions can be summarized as follows:

(1) In a plasma process, the removal of toluene in the fuel gas atmosphere requires more energy input than that in $\mathrm{N}_{2}$ atmosphere.

(2) Temperature is an important factor in a plasma-catalytic process. A significantly increased toluene removal efficiency as well as the obvious synergetic effect can be observed when the reaction temperature is above a threshold value. A high reaction temperature is required to achieve a desirable tar removal efficiency.

(3) The combination of plasma and catalyst can effectively remove toluene in a fuel gas atmosphere. Toluene removal efficiency of $91.7 \%$ and energy efficiency of $16.9 \mathrm{~g} / \mathrm{kWh}$ were achieved in the DBD reactor combined with $5 \mathrm{wt} \%$ $\mathrm{Ni} / \mathrm{Y}-\mathrm{Al}_{2} \mathrm{O}_{3}$. Moreover, the use of the catalyst with higher Ni loadings led to a better performance.

(4) The methanation of the fuel gas was observed in the toluene removal process, which could be enhanced by the 
plasma-catalytic process as well as the increased temperature. However, the low $\mathrm{H}_{2} / \mathrm{CO}$ ratio of the fuel gas resulted in low CO conversion and severe carbon deposition.

(5) Two gaseous products of $\mathrm{C}_{2} \mathrm{H}_{2}$ and $\mathrm{C}_{2} \mathrm{H}_{6}$ were found at the outlet of the plasma-catalyst reactor, which were believed to be partly derived from the dissociation of toluene in the plasma process.

(6) The liquid products were generated from the recombination of intermediate molecular fragments derived from the dissociation of toluene molecules, some of the intermediate compounds were identified and the possible mechanisms and pathways of toluene destruction were proposed and elucidated.

\section{AUTHOR INFORMATION}

Corresponding Author

*E-mail: xieji@ms.giec.ac.cn.

\section{Notes}

The authors declare no competing financial interest.

\section{ACKNOWLEDGEMENTS}

This wok was supported by the National Natural Science Foundation of China (Grant No. 51576200, 51811530317), the Natural Science Foundation of Guangdong Province of China (Grant No. 2017B030308002) and Royal Society International Exchanges 2017 Cost Share (China) (IEC\NSFC\170654).

\section{References}

[1] Deshmukh R, Jacobson A, Chamberlin C, Dan K. Thermal gasification or direct combustion? Comparison of advanced cogeneration systems inthe sugarcane industry. Biomass \& Bioenergy 2013;55(55):163-74.

[2] Kumar A, Demirel Y, Jones DD, Hanna MA. Optimization and economic evaluation of industrial gas production and combined heat and power generation from gasification of corn stover and distillers grains. Bioresource Technology

2010;101(10):3696-701.

[3] Leibbrandt NH, Aboyade AO, Knoetze JH, Görgens JF. Process efficiency of biofuel production via gasification and FischerTropsch synthesis. Fuel 2013;109(7):484-92.

[4] Han J, Kim H. The reduction and control technology of tar during biomass gasification/pyrolysis: An overview. Renewable \& Sustainable Energy Reviews 2008;12(2):397-416.

[5] Li C, Suzuki K. Tar property, analysis, reforming mechanism and model for biomass gasification-An overview. Renewable \& Sustainable Energy Reviews 2009;13(3):594-604.

[6] Anis S, Zainal ZA. Tar reduction in biomass producer gas via mechanical, catalytic and thermal methods: A review. Renewable and Sustainable Energy Reviews 2011;15(5):2355-77. 
[7] Chen Y, Luo Y-h, Wu W-g, Su Y. Experimental Investigation on Tar Formation and Destruction in a Lab-Scale Two-Stage Reactor. Energy \& Fuels 2009;23(9):4659-67.

[8] Shen Y, Yoshikawa K. Recent progresses in catalytic tar elimination during biomass gasification or pyrolysis-A review. Renewable \& Sustainable Energy Reviews 2013;21:371-92.

[9] Harling AM, Glover DJ, Whitehead JC, Zhang K. Novel Method for Enhancing the Destruction of Environmental Pollutants by the Combination of Multiple Plasma Discharges. Environmental Science \& Technology 2008;42(12):4546-50.

[10] Saleem F, Zhang K, Harvey A. Role of $\mathrm{CO}_{2}$ in the Conversion of Toluene as a Tar Surrogate in a Nonthermal Plasma Dielectric Barrier Discharge Reactor. Energy \& Fuels 2018;32(4):5164-70.

[11] Liu L, Wang Q, Ahmad S, Yang X, Ji M, Sun Y. Steam reforming of toluene as model biomass tar to $\mathrm{H}_{2}$-rich syngas in a DBD plasma-catalytic system. Journal of the Energy Institute 2017;

[12] Liu SY, Mei DH, Nahil MA, Gadkari S, Gu S, Williams PT, et al. Hybrid plasma-catalytic steam reforming of toluene as a biomass tar model compound over $\mathrm{Ni} / \mathrm{Al}_{2} \mathrm{O}_{3}$ catalysts. Fuel Processing Technology 2017;166:269-75.

[13] Nair SA, Pemen AJM, Yan K, van Gompel FM, van Leuken HEM, van Heesch EJM, et al. Tar removal from biomassderived fuel gas by pulsed corona discharges. Fuel Processing Technology 2003;84(1-3):161-73.

[14] Zhu F, Li X, Zhang H, Wu A, Yan J, Ni M, et al. Destruction of toluene by rotating gliding arc discharge. Fuel 2016;176:7885 .

[15] Liu S, Mei D, Wang L, Tu X. Steam reforming of toluene as biomass tar model compound in a gliding arc discharge reactor. Chemical Engineering Journal 2017;307:793-802.

[16] Van Durme J, Dewulf J, Leys C, Van Langenhove H. Combining non-thermal plasma with heterogeneous catalysis in waste gas treatment: A review. Applied Catalysis B: Environmental 2008;78(3-4):324-33.

[17] Whitehead JC. Plasma catalysis: a solution for environmental problems. Pure and Applied Chemistry 2010;82(6):1329-36.

[18] Wang Q, Yan BH, Jin Y, Cheng Y. Dry Reforming of Methane in a Dielectric Barrier Discharge Reactor with $\mathrm{Ni}^{2} \mathrm{Al}_{2} \mathrm{O}_{3}$ Catalyst: Interaction of Catalyst and Plasma. Energy \& Fuels 2009;23(8):4196-201.

[19] Tu X, Whitehead JC. Plasma-catalytic dry reforming of methane in an atmospheric dielectric barrier discharge:

Understanding the synergistic effect at low temperature. Applied Catalysis B: Environmental 2012;125(Supplement C):439-48.

[20] Nair SA. Corona plasma for tar removal. Eindhoven University of Technology, Eindhoven, The Netherlands, 2004.

[21] Zoran F, John JC. Microdischarge behaviour in the silent discharge of nitrogen - oxygen and water - air mixtures. Journal of Physics D: Applied Physics 1997;30(5):817.

[22] Goujard V, Tatibouët JM, Batiot-Dupeyrat C. Carbon Dioxide Reforming of Methane Using a Dielectric Barrier Discharge Reactor: Effect of Helium Dilution and Kinetic Model. Plasma Chemistry \& Plasma Processing 2011;31(2):315-25.

[23] Abdelaziz AA, Seto T, Abdel-Salam M, Otani Y. Influence of $\mathrm{N}_{2} / \mathrm{O}_{2}$ Mixtures on Decomposition of Naphthalene in Surface Dielectric Barrier Discharge Based Reactor. Plasma Chemistry and Plasma Processing 2014;34(6):1371-85.

[24] Yu L, Li XD, Tu X, Wang Y, Lu SY, Yan JH. Decomposition of Naphthalene by DC Gliding Arc Gas Discharge. Journal of Physical Chemistry A 2010;114(1):360-8.

[25] Hasler P, Nussbaumer T. Gas cleaning for IC engine applications from fixed bed biomass gasification. Biomass and Bioenergy 1999;16(6):385-95.

[26] Zheng C, Zhu X, Gao X, Liu L, Chang Q, Luo Z, et al. Experimental study of acetone removal by packed-bed dielectric barrier discharge reactor. Journal of Industrial and Engineering Chemistry 2014;20(5):2761-8.

[27] Zhao A, Ying W, Zhang H, Ma H, Fang D. Ni- $\mathrm{Al}_{2} \mathrm{O}_{3}$ catalysts prepared by solution combustion method for syngas methanation. Catalysis Communications 2012;17:34-8.

[28] Patcas F, Hönicke D. Effect of alkali doping on catalytic properties of alumina-supported nickel oxide in the selective oxidehydrogenation of cyclohexane. Catalysis Communications 2005;6(1):23-7.

[29] Zhang J, Xu H, Jin X, Ge Q, Li W. Characterizations and activities of the nano-sized Ni/ $\mathrm{Al}_{2} \mathrm{O}_{3}$ and Ni/La- $\mathrm{Al}_{2} \mathrm{O}_{3}$ catalysts for NH3 decomposition. Applied Catalysis A: General 2005;290(1):87-96.

[30] Xiao G, Xu W, Wu R, Ni M, Du C, Gao X, et al. Non-Thermal Plasmas for VOCs Abatement. Plasma Chemistry and Plasma Processing 2014;34(5):1033-65.

[31] Tu X, Gallon HJ, Twigg MV, Gorry PA, Whitehead JC. Dry reforming of methane over a Ni/ $\mathrm{Al}_{2} \mathrm{O}_{3}$ catalyst in a coaxial 
dielectric barrier discharge reactor. Journal of Physics D Applied Physics 2011;44(27):274007.

[32] Bityurin VA, Filimonova EA, Naidis GV. Simulation of Naphthalene Conversion in Biogas Initiated by Pulsed Corona Discharges. Ieee Transactions on Plasma Science 2009;37(6):911-9.

[33] Abdelaziz AA, Seto T, Abdel-Salam M, Otani Y. Influence of nitrogen excited species on the destruction of naphthalene in nitrogen and air using surface dielectric barrier discharge. Journal of Hazardous Materials 2013;246-247:26-33.

[34] Harling AM, Demidyuk V, Fischer SJ, Whitehead JC. Plasma-catalysis destruction of aromatics for environmental clean-up: Effect of temperature and configuration. Applied Catalysis B Environmental 2008;82(3-4):180-9.

[35] Demidiouk V, Jae Ou C. Decomposition of volatile organic compounds in plasma-catalytic system. IEEE Transactions on Plasma Science 2005;33(1):157-61.

[36] Harling AM, Kim H-H, Futamura S, Whitehead JC. Temperature Dependence of Plasma-Catalysis Using a Nonthermal, Atmospheric Pressure Packed Bed; the Destruction of Benzene and Toluene. The Journal of Physical Chemistry C 2007;111(13):5090-5.

[37] Blackbeard T, Demidyuk V, Hill SL, Whitehead JC. The Effect of Temperature on the Plasma-Catalytic Destruction of Propane and Propene: A Comparison with Thermal Catalysis. Plasma Chemistry and Plasma Processing 2009;29(6):411.

[38] Jo S, Kim T, Lee DH, Kang WS, Song YH. Effect of the Electric Conductivity of a Catalyst on Methane Activation in a Dielectric Barrier Discharge Reactor. Plasma Chemistry \& Plasma Processing 2014;34(1):175-86.

[39] Ding M, Tu J, Zhang Q, Wang M, Tsubaki N, Wang T, et al. Enhancement of methanation of bio-syngas over CeO2modified $\mathrm{Ni} / \mathrm{Al}_{2} \mathrm{O}_{3}$ catalysts. Biomass and Bioenergy 2016;85(Supplement C):12-7.

[40] Seemann MC, Schildhauer TJ, Biollaz SMA. Fluidized Bed Methanation of Wood-Derived Producer Gas for the Production of Synthetic Natural Gas. Industrial \& Engineering Chemistry Research 2010;49(15):7034-8.

[41] Choudhury MBI, Ahmed S, Shalabi MA, Inui T. Preferential methanation of CO in a syngas involving $\mathrm{CO}_{2}$ at lower temperature range. Applied Catalysis A General 2006;314(1):47-53.

[42] Kopyscinski J, Schildhauer TJ, Biollaz SMA. Production of synthetic natural gas (SNG) from coal and dry biomass - A technology review from 1950 to 2009. Fuel 2010;89(8):1763-83.

[43] Ding M-Y, Tu J-Y, Wang T-J, Ma L-L, Wang C-G, Chen L-G. Bio-syngas methanation towards synthetic natural gas (SNG) over highly active $\mathrm{Al}_{2} \mathrm{O}_{3}-\mathrm{CeO}_{2}$ supported Ni catalyst. Fuel Processing Technology 2015;134(Supplement C):480-6.

[44] Blin-Simiand N, Jorand F, Magne L, Pasquiers S, Postel C, Vacher J-R. Plasma Reactivity and Plasma-Surface Interactions During Treatment of Toluene by a Dielectric Barrier Discharge. Plasma Chemistry and Plasma Processing 2008;28(4):429-66.

[45] Chen T, Liu H, Shi P, Chen D, Song L, He H, et al. $\mathrm{CO}_{2}$ reforming of toluene as model compound of biomass tar on Ni/Palygorskite. Fuel 2013;107(Supplement C):699-705.

[46] Mcenally CS, Pfefferle LD. Experimental Assessment of Naphthalene Formation Mechanisms in Non-Premixed Flames. Combustion Science \& Technology 1997;128(1-6):257-78. 